Georgia State University

ScholarWorks @ Georgia State University

3-1-2012

\title{
Inducing Risk Neutral Preferences with Binary Lotteries: A Reconsideration
}

\author{
Glenn Harrison \\ Georgia State University \\ Jimmy Martínez-Correa \\ Copenhagen Business School \\ Todd Swarthout \\ Georgia State University
}

Follow this and additional works at: https://scholarworks.gsu.edu/excen_workingpapers

\section{Recommended Citation}

Harrison, Glenn; Martínez-Correa, Jimmy; and Swarthout, Todd, "Inducing Risk Neutral Preferences with Binary Lotteries: A Reconsideration" (2012). ExCEN Working Papers. 50.

https://scholarworks.gsu.edu/excen_workingpapers/50

This Article is brought to you for free and open access by the Experimental Economics Center at ScholarWorks @ Georgia State University. It has been accepted for inclusion in ExCEN Working Papers by an authorized administrator of ScholarWorks @ Georgia State University. For more information, please contact scholarworks@gsu.edu. 


\title{
Inducing Risk Neutral Preferences with Binary Lotteries:
}

\section{A Reconsideration}

\author{
by \\ Glenn W. Harrison, Jimmy Martínez-Correa and J. Todd Swarthout ${ }^{\dagger}$
}

March 2012

\section{ABSTRACT.}

We evaluate the binary lottery procedure for inducing risk neutral behavior. We strip the experimental implementation down to bare bones, taking care to avoid any potentially confounding assumption about behavior having to be made. In particular, our evaluation does not rely on the assumed validity of any strategic equilibrium behavior, or even the customary independence axiom. We show that subjects sampled from our population are generally risk averse when lotteries are defined over monetary outcomes, and that the binary lottery procedure does indeed induce a statistically significant shift towards risk neutrality. This striking result generalizes to the case in which subjects make several lottery choices and one is selected for payment.

† Department of Risk Management \& Insurance and Center for the Economic Analysis of Risk, Robinson College of Business, Georgia State University, USA (Harrison); Department of Risk Management \& Insurance, Robinson College of Business, Georgia State University, USA (MartínezCorrea); and Department of Economics, Andrew Young School of Policy Studies, Georgia State University, USA (Swarthout). E-mail contacts: gharrison@gsu.edu, jimmigan@gmail.com and swarthout@gsu.edu. We are grateful to Joy Buchanan, Jim Cox, Melayne McInnes and Stefan Trautman for comments. 


\section{Table of Contents}

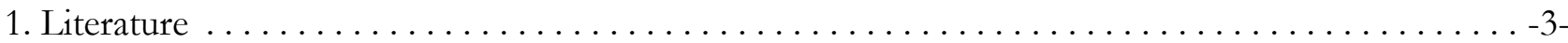

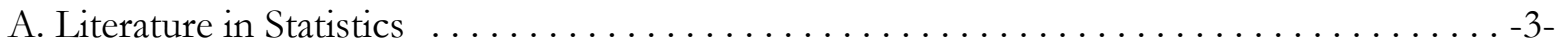

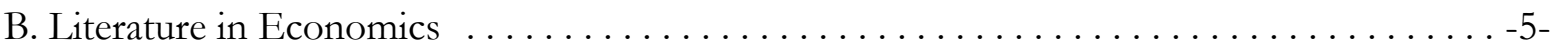

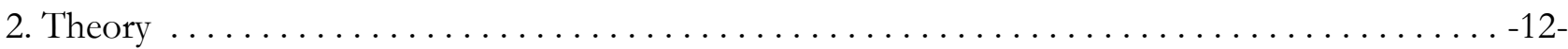

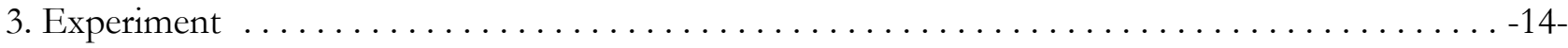

4. Results $\ldots \ldots \ldots \ldots \ldots \ldots \ldots \ldots \ldots \ldots \ldots \ldots \ldots \ldots \ldots \ldots \ldots \ldots \ldots \ldots \ldots . .20$.

A. Do Subjects Pick the Lottery With the Higher Expected Value? . . . . . . . . . . . . -21-

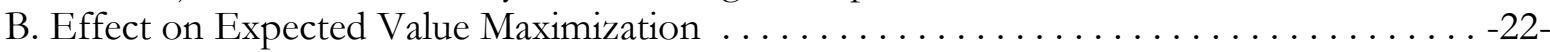

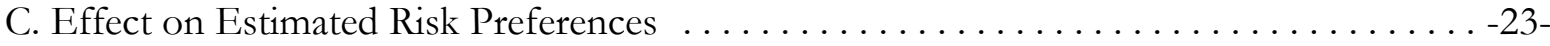

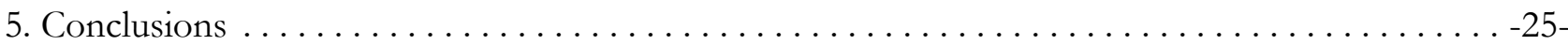

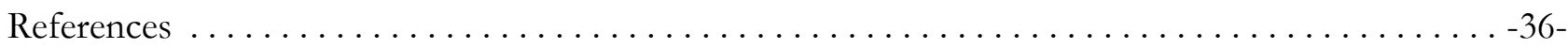

Appendix A: Instructions (NOT FOR PUBLICATION) $\ldots \ldots \ldots \ldots \ldots \ldots \ldots \ldots \ldots \ldots \ldots \ldots .39$.

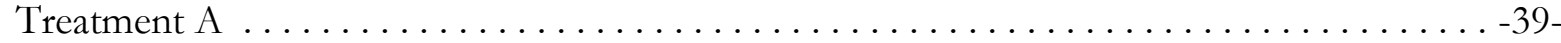

Treatment B ...................................... $40-$

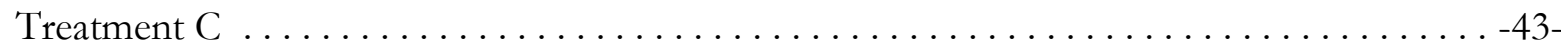

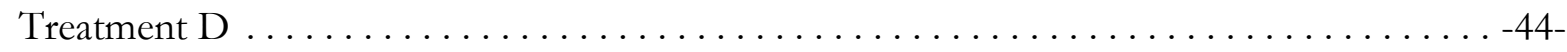

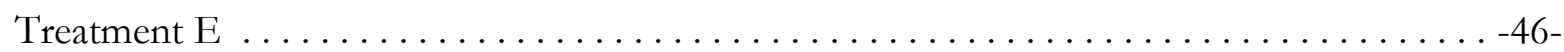

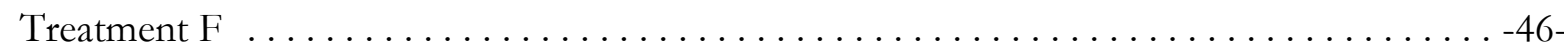

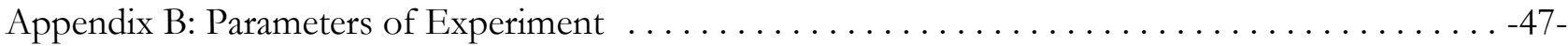

Appendix C: Structural Estimation of Risk Preferences (NOT FOR PUBLICATION) . . . . . . . -49- 
Experimental economists would love to have a procedure to induce linear utility functions.

Many inferences in economics depend on risk premia and the extent of diminishing marginal utility. ${ }^{1}$ In fact, the settings in which these do not play a confounding role are the special case. Procedures to induce linear utility functions have a long history, with the major contributions being Smith [1961], Roth and Malouf [1979] and Berg, Daley, Dickhaut and O’Brien [1986]. Unfortunately, these “lottery procedures" have come under attack on behavioral grounds: the consensus appears to be that they may be fine in theory, but just do not work as advertized.

We review that evidence. The first point to note is that the consensus is not unanimous. There are several instances where the lottery procedures have indeed shifted choices in the predicted direction, and simple explanations provided to explain why others might have generated negative findings (e.g., Rietz [1993]). The second point is the most important for us: none of the prior tests have been pure tests of the lottery procedure. Every previous test requires one or more of three auxiliary assumptions:

1. That the utility functions defined over money, or other consequences, are in fact non-linear, so that there is a behavioral problem to be solved with the lottery procedure;

2. That behavior is characterized according to some strategic equilibrium concept, such as Nash Equilibrium; and/or

3. That the "independence axiom" holds when subjects in experiments are paid for 1 in $\mathrm{K}$ choices, where $\mathrm{K}>1$.

Selten, Sadrieh and Abbink [1999; Table 1] pointed out the existence of the first two confounds in the previous literature. Their own test employed the third assumption as an auxiliary assumption, and found no evidence to support the use of the lottery procedure. We propose tests that avoid all three

${ }^{1}$ Risk attitudes are only synonymous with diminishing marginal utility under expected utility theory. But diminishing marginal utility also plays a confounding role under many of the prominent alternatives to expected utility theory, such as rank-dependent utility theory and prospect theory. 
assumptions. To our knowledge, these are the first such tests.

Our procedures are very simple. First, we ask subjects in one treatment to make a single choice over a pair of lotteries defined over money and objective probabilities. They make no other choices, hence we do not need to rely on the Random Lottery Incentive Method (RLIM) and the Independence Axiom (IA); these terms are defined more formally later. This treatment constitutes a theoretical and behavioral baseline, to allow us to establish that the typical decision maker in our population exhibits a concave utility function over these prizes. $^{2}$

Second, we ask subjects in another treatment to make the same choices but where they earn points instead of money, and these points convert into increased probability of winning some later, binary lottery. The choices are the same in the sense that they have the same numerical relationship between consequences (e.g., if one lottery had prizes of $\$ 70$ or $\$ 35$, the variant would have prizes of 70 or 35 points), and the same objective probabilities. The subjects are also drawn at random from the same population as the control treatment. Between-subjects tests are necessary, of course, if one is to avoid the RLIM procedure and having to assume the IA.

At this point there are two ways to evaluate the lottery procedure. One is to see if behavior in the points tasks matches the theoretical prediction of choosing whichever lottery had the highest Expected Value (EV). The other is to see if it induces significantly less concave utility functions than the baseline task, and generates statistical estimates consistent with a linear utility function. We apply both approaches, which have relative strengths and weaknesses, and find that the lottery procedure works virtually exactly as advertized.

In section 1 we review the literature on the lottery procedure, in section 2 we review the theory underlying the procedure, in section 3 we present our experimental design, and in section 4 we evaluate

\footnotetext{
${ }^{2}$ This is also true if we estimate a structural model with rank-dependent probability weighting. All of our choices involve the gain domain, so the traditional form of loss aversion in prospect theory does not apply.
} 
the results. Section 1 makes the point that the procedure has an impressive lineage in statistics, and that all of the previous tests in economics require auxiliary assumptions. Section 2 clarifies the axiomatic basis of behavior and the distinct roles in the experiment for the IA and a special binary version of the Reduction of Compound Lotteries (ROCL) axiom. It also explains the relationship between the lottery procedure and non-standard models of decision making under risk: does the lottery procedure help induce risk neutrality under rank-dependent models and prospect theory? The answer is "yes," under some weak conditions.

\section{Literature}

\section{A. Literature in Statistics}

Cedric Smith [1961] appears to have been the first to explicitly pose the lottery procedure as a way of inducing risk neutral behavior. He considers the issue of two individuals placing bets over some binary event. The person whose subjective probability we seek to elicit is Bob, and the experimenter is Charles. There is a third person, an Umpire, who is the funding agency providing the subject fees.

Choices over Savage-type lotteries are elicited from Bob, and inferences then made about his subjective probabilities. But the reward can, of course, affect the utilities of Bob, so how does one control for that confound when inferring Bob’s subjective probabilities?

Stated differently, is there some way to make sure that the choices over bets do not depend on the reward, but only on the subjective probability of the event? Smith [1961; p.13] proposes a solution:

To avoid these difficulties it is helpful to use the following device, adapted from Savage [1954]. Instead of presenting cash to Bob and Charles, the Umpire takes 1 kilogram of beeswax (of negligible value) and hides within it at random a very small but valuable diamond. He divides the wax into two parts, presenting one to each player, and instructs them to use it for stakes. After all bets have been settled, the wax is melted down and whoever has the diamond keeps it. Effectively this means that if, say, Bob gives Charles y grams of wax, he increases Charles's chance of winning the diamond by $y / 1000$. [..] Hence using beeswax or "probability currency" the acceptability of a bet depends on the odds [...], and not on the stake ... 
It should be noted that this solution does two things, each of which play a role in the later economics literature. Not only can we infer Bob’s subjective probabilities from his choices over the bets without knowing (much about) his utility function, but the same is true with respect to Charles. Thus, in the hands of Roth and Malouf [1979], we can evaluate the expected utility of two bargaining agents with this device. ${ }^{3}$ We are interested here just in the first part of this procedure, the knowledge it provides of Bob's utility scale over these two prizes.

Of course, the reference to Savage [1954] is tantalizing, but that is a large and dense book! There are three places in which the concept appears to be implied. The first, of course, is the core axiom (P5), introduced in $\$ 3.2$, and its use in many proofs. This axiom requires that there be at least two consequences such that the decision-maker strictly prefers one consequence to the other. ${ }^{4}$ The formal mathematical use of this axiom in settings in which there are three or more consequences makes it clear that probabilities defined over any such pair can be used to define utilities that can be scaled by some utility function when other axioms deal with the other consequences. Of course, this formal use is far from the operational lottery procedure, but is suggestive.

The second is the related discussion in $\$ 5.5$ of the application of axiom (P5) in a "small world" setting in which there are in fact many consequences. Specifically, Savage offers the metaphor of tickets in distinct lotteries for nothing, a sedan, a convertible, or a thousand dollars. The decision maker selects one of these four lotteries, and wins one of these four consequences with some (subjective) probability. ${ }^{5}$

${ }^{3}$ There is one change from the betting metaphor developed by Smith [1961; p.4]. He has the Umpire pose subjective probabilities, not Charles. In bargaining games, Bob and Charles directly negotiate on these probabilities under some protocol.

${ }^{4}$ The need for (P5), however minimal, is why we referred in the previous paragraph to the lottery procedure not requiring that we know much about the utility function of the decision maker. It does require that (P5) apply for the two prizes, so that we can assign distinct real values to them.

${ }^{5}$ The consequence "nothing" is used in context to locate this small world experiment in the grand world that the decision maker inhabits. Thus "nothing" means nothing from the experimental task, or the maintenance of the grand world status quo. Little would be lost in our context by replacing "nothing" with "one penny." 
So the lottery is between the status quo and the status quo plus the single consequence associated with the lottery ticket type chosen.

The third is more explicit, and pertains to the discussion of controlling for the utility of the decision maker in applications of the minimax rule in $\$ 13.4$. He proposed (p. 202) three solutions to this issue, the first of which defines what he is after (a linear utility scale) and the third of which presents the lottery procedure:

Three special circumstances are known to me under which escape from this dilemma is possible. First, there are problems in which some straightforward commodity, such as money, lives, man hours, hospital bed days, or submarines sighted, is obviously so nearly proportional to utility as to be substitutable for it. [...] Third, there are many important problems, not necessarily lacking in richness of structure, in which there are exactly two consequences, typified by overall success or failure in a venture. In such a problem, as I have heard J. von Neumann stress, the utility can, without loss of generality, be set equal to 0 on the less desired and equal to 1 on the more desired of the two consequences.

Yet another tantalizing bibliographic thread!

\section{B. Literature in Economics}

Roth and Malouf [1979] (RM) independently introduced the Smith [1961] procedure into the economics literature. The procedure is simple, and has subsequently been employed by many experimenters. Their experiment involved two subjects bargaining over some pie. Since most of the cooperative game theoretic solution concepts require that subjects bargain directly over utilities or expected utilities, RM devised a procedure for ensuring that this was the case if subjects obeyed the axioms of expected utility theory. Their idea was to provide each subject $i$ with a high prize $M_{i}$ and a low prize $m_{i}$, where $M_{i}>m_{i}$ for each subject $i$. Although not essential, let these prizes be money. Each subject was then to engage in a bargaining process to divide 100 lottery tickets between the two subjects. Each lottery ticket that the subject received from the bargaining process resulted in them having a 1 percentage point chance of receiving the high prize instead of the low prize. Thus, if subject 
$i$ received 83 of the lottery tickets, he would receive the high prize with probability 0.83 and the low prize with residual probability 0.17 . Since utility functions are arbitrary up to a linear transformation, one could set the utility value of the high prize to 1 for each player and the utility value of the low prize to 0 for each player. Thus bargaining over the division of 100 lottery tickets means that the subjects are bargaining over the expected utility to themselves and the other player.

There are several remarkable and related features of this elegant design. First, no player has to know the value of the prizes available to the other player in order to bargain over expected utility uniquely. Whether the other person's high prize is the same or double my high prize, I can set his utility of receiving that prize to 1 . All that is required are the assumptions of non-satiation in the prize and the invariance of equivalent utility representations. Second, and related to this first point but separable, the prizes can differ. Third, the subject does not even have to know the value of the monetary prizes to himself, just that there will be "more of it" if he wins the lottery and that "it" is something in which he is not satiated.

The experiments of RM also revealed some important behavioral features of applying this procedure in experiments. When subjects bargained in a relatively unstructured manner, in a setting in which they did not know the value of the prizes to the other player, they generally tended to bargain to equal-split outcomes of the lottery tickets, which translate into equal splits of expected utility to each player. But when subjects received more information than received (cooperative) theory typically required, specifically the value of the monetary prizes to the other subjects, outcomes converged even more clearly to the equal-split outcome when the prizes were identical. But when the prizes were not identical, there were two outcomes, reflected in a bi-modality of the observed data. One mode involved subjects bargaining to an equal-split of tickets, and the other mode involved subjects bargaining to an unequal-split of tickets that tended to equalize the expected monetary gain to each player. In other words, the subjects behaved as if using the information on the value of the prizes, and the interpersonal 
comparability of the utility ${ }^{6}$ of those prizes, to arrive at an outcome that was fair in terms of expected monetary gain. Of course, this fair outcome in terms of expected monetary gain coincided with the fair outcome in terms of expected utility when subjects were told the value of monetary prizes and that they were the same for both players.

There are two important insights from their results for our purposes. First, it is feasible to modify an experimental game to ensure that the payoffs of subjects are defined in terms of utility and expected utility. We review procedures employed by several experimenters interested in noncooperative games below. Second, the provision of information that allows subjects to make interpersonal comparisons of utility can add a possible confound. That is, the provision of "more information than theory assumes is needed for subjects to know utility payoffs" can lead to subjects employing fairness rules or norms that rely on interpersonal comparability of utility. ${ }^{7}$

The RM procedure was generalized by Berg, Daley, Dickhaut and O’Brien [1986], albeit in the context of games against Nature. Their idea was that subjects would make choices over lotteries defined in terms of points instead of pennies, and that their accumulated points earnings would be then converted to money using an exchange rate function. If this function was linear, then risk neutrality would be induced. If this function was convex (concave), risk-loving (risk averse) preferences would be induced. By varying the function one could, in principle, induce any specific risk attitude.

Unfortunately, the Berg, Daley, Dickhaut and O’Brien [1986] procedure came under fire “immediately" from Cox, Smith and Walker [1985]. They applied the procedure in two treatments in

\footnotetext{
${ }^{6}$ A dollar note given to me is the same dollar note that could have been given to you, and the transform from money to utility is unique.

${ }^{7} \mathrm{RM}$ point this out quite clearly, and proceed to develop an alternative to the standard cooperative bargaining solution concept that allows subjects to make such interpersonal comparisons. These differences are of some significance for policy. For example, Harrison and Rutström [1992] apply the two concepts developed by RM to predict outcomes of international trade negotiations, showing how comparable information on the U.S. dollar-equivalent of the "equivalent variation" of alternative trade policies can be used to influence negotiated outcomes.
} 
which they also had identical, paired treatments that did not use the procedure. The context of their test was an experiment in which four subjects bid for a single object using first-price sealed-bid rules, and values were induced randomly in an independent and private manner. In one treatment they generated random values over 20 periods, and paid subjects their monetary profits; in the paired treatment they used the same 80 random valuations, applied in the same order but to a different pool of subjects, but used the lottery procedure to generate risk-neutral bidding. They found no support for the hypothesis that the lottery procedure generated risk neutral bidding. Related tests of the lottery procedure, conditional on assumptions about bidding behavior in auctions, were provided by Walker, Smith and Cox [1990] and Cox and Oaxaca [1995]. One important feature of the experimental tests of Walker, Smith and Cox [1990] is that 5 of their 15 experiments used subjects that had demonstrated, in past experiments, "tight consistency" with Nash Equilibrium bidding predictions. Thus the use of those subjects could be viewed a priori as recognizing, and mitigating, the confounding effects of those auxiliary assumptions on tests of the lottery procedure. Rietz [1993] provides a careful statement of the detailed procedural features of these earlier, discouraging tests of the lottery procedure, and their role in it's efficacy; we review his main findings below.

The controversy over the use of the risk-inducement technique led many experimental economists at the time to abandon it. Although not often stated, the folklore was clear: since it had not been advocated as necessary to use, why bother? Moreover, the procedures for inducing risk aversion or risk loving behavior did add a cognitive layer of complexity to procedures that one might want to avoid unless necessary.

Several experimenters did use the lottery procedure in tandem with experiments that did not attempt to control for risk aversion: in effect, staying directly out of the debate over the validity of the 
procedure but checking if it made any difference. ${ }^{8}$ For example, Harrison [1989] ran his first-price sealed bid auction with and without the lottery procedure to induce risk neutrality, and managed to generate enough debate on other grounds that nobody cared if the procedure had any effect! Similarly, Harrison and McCabe [1992] ran their alternating-offer, non-cooperative bargaining experiments "both ways," and found no difference in behavior. ${ }^{9}$

Ochs and Roth [1989] is an important study because it was the first foray of Alvin Roth, the "R" in RM, into non-cooperative experimental games, and did not employ the binary lottery procedure developed by RM. They explicitly make “... the assumption that the bargainer's utility is measured by their monetary payoffs" (p. 359), but have nothing else to say on the matter. This methodological discontinuity between RM and Ochs and Roth [1989] is an interesting puzzle, and may have been prompted by the acrimonious debate generated by Cox, Smith and Walker [1985] and the fact that none of the prior non-cooperative bargaining experiments that Ochs and Roth [1989] were generalizing had worried about the possible difference.

There have been several experiments in which the lottery procedure has been employed exclusively, most notably Cooper, DeJong, Forsythe and Ross [1989][1990][1992][1993]. ${ }^{10}$ They had a very clear sense of why some such procedure was needed, and implemented it in a simple manner:

\footnotetext{
${ }^{8}$ Braunstein and Scotter [1982] employed an early "with and without" design, in the context of individual choice experiments examining job search.

9 On the other hand, the weight of experimental procedure was against the use of such procedures, leading Harrison and McCabe [1996; p.315] to cave in and offer an invalid rationalization of their choice not to use the lottery procedure: "We elected not to use the lottery procedure of Roth and Malouf [1979] to induce risk-neutral behaviour. None of the previous studies of Ultimatum bargaining have used it, and risk attitudes should not matter for the standard game-theoretic prediction that we are testing." The final phrase is technically correct, but only because the subgame perfect Nash equilibrium prediction calls for one player to offer essentially nothing to the other player, and to take essentially all of the pie for himself. Thus one does not need to know what utility function each player has, since the prediction calls for the players to get utility outcomes that can always be normalized to "essentially zero" and "essentially one."

${ }^{10}$ Harrison [1994] employed it in tests of a non-strategic setting, where the predictions of expected utility theory depended on risk attitudes. He recognized that the experiment therefore became a test of the joint hypothesis that the risk inducement procedure worked and that expected utility theory applied to the lottery choices under study.
} 
Each game was defined to be one of complete information, because each player's payoff matrix was common knowledge, and the numerical payoffs represented a player's utility if the corresponding strategies were chosen. To accomplish this, we induced payoffs in terms of utility using the procedure of [RM...]. With this procedure, each player's payoff is given in points; these points determine the probability of the player winning a monetary prize. At the end of each period of each game, we conducted a lottery in which "winning" players received $\$ 1.00$ or $\$ 2.00$, depending on the session, and "losing" players received $\$ 0.00$. The probability of winning was given by dividing the points the player had earned by 1,000. Since expected utility is invariant with respect to linear transformations, this procedure ensures that, when players maximize their expected utility, they maximize the expected number of points in each game, regardless of their attitude to risk. [1993; p.1307, footnotes omitted]

Their experiments involved simple normal form games in which the points payoffs ranged from 0 up to 1000 , with many around the 300 to 600 range, and subject participated sequentially in 30 games against different opponents. One important feature of their implementation is that the players could engage in interpersonal comparisons of utility, since they knew that the prizes each subject faced were the same.

Rietz [1993] examines the lottery procedure in the context of auxiliary assumptions about equilibrium bidding behavior in first-price sealed bid auctions, as in Harrison [1989], but uncovers some interesting and neglected behavioral properties of the procedure. ${ }^{11}$ First, if subjects are exposed to the task with monetary prizes, it is difficult to change their behavior with the lottery procedure. Thus there is a behavioral hysteresis or order effect. Second, if subjects have not been previously exposed to the task with monetary prizes, then the lottery procedure works as advertized. Finally, if one "trains subjects up" in the lottery procedure in a dominant-strategy context (e.g., a second-price sealed bid auction), then it's performance "travels" to a different setting and it works as advertized in a strategic context in which there is no dominant strategy (e.g., a first-price sealed bid auction).

On the other hand, Cox and Oaxaca [1995] criticize the estimator used by Rietz [1993]. He used

${ }^{11}$ These properties were identified in an attempt to explain the different conclusions drawn from the same general environment by Cox, Smith and Walker [1985] and Walker, Smith and Cox [1990]. 
a Least-Absolute-Deviations (LAD) estimator that was applied to data that had already been normalized by dividing observed bids by item values for the bidder, in contract to the earlier use of Ordinary Least Squares (OLS) on untransformed data by Walker, Smith and Cox [1990]. Cox and Oaxaca [1995] argue that OLS is not obviously inferior to LAD in this context, and that there are tradeoffs of one over the other (e.g., if heteroskedasticity is not eliminated, which of OLS or LAD is easier to evaluate for heteroskeasticity, and which has better out-of-sample predictive accuracy?). It is apparent that both OLS and LAD are decidedly second-best if one could estimate a structural model that directly respects the underlying theory, as in Harrison and Rutström [2008; §3.6].

Cox and Oaxaca [1995] also point out that the lottery procedure implies both a "zero intercept" and a "unit slope" in behavior compared to the risk-neutral Nash equilibrium bid predictions, and that Rietz [1993] only tested for the latter. Hence his tests are incomplete as a conceptual matter, even if one puts aside questions about the "best" estimator for these tests.

Berg, Rietz and Dickhaut [2008] collect and review all of the studies testing the lottery procedure, and argue that the evidence against it's efficacy is not so clear as many have claimed.

Selten, Sadrieh and Abbink [1999] is the first study to stress that all previous tests of the lottery procedure have involved confounding assumptions, even if there had been attempts in some, such as Walker, Smith and Cox [1990], to mitigate them. They presented subjects with 36 paired lottery choices, and 14 lottery valuation tasks. The latter valuation tasks employed the Becker-DeGroot-Marschak elicitation procedure, which has poor behavioral incentives even if it is theoretically incentive compatible (Harrison [1992]). ${ }^{12}$ They calculate a statistic for each subject over all 50 tasks: the difference between the maximum EV over all 50 choices minus the actual EV for the observed choices. If the lottery procedure is generating risk neutral behavior then it should lead to a reduction in this

${ }^{12}$ Given these concerns, and the detailed listing of data by Selten, Sadrieh and Abbink [1999; Appendix B], it would be useful to re-evaluate their conclusions by just looking at the 36 binary choices. 
statistic, compared to treatments using monetary prizes directly. Focusing on their treatments in which statistical measures about the lotteries were not made available, they had 48 subjects in each treatment. They find that the subjects in the lottery procedure actually had larger losses relative to the maximum if they had been following a strategy of choosing in a risk neutral manner. These differences were statistically evaluated using non-parametric two-sample Wilcoxon-Mann-Whitney tests of the null hypothesis that they were drawn from the same distribution; the one-sided $p$-value was lower than 0.05 . Not only is the lottery procedure failing to induce risk neutrality, it appears to be moving subjects in the wrong direction!

\section{Theory}

The Reduction of Compound Lotteries (ROCL) axiom states that a decision-maker is indifferent between a compound lottery and the actuarially-equivalent simple lottery in which the probabilities of the two stages of the compound lottery have been multiplied out. To use the language of Samuelson [1952; p.671], the former generates a compound income-probability-situation, and the latter defines an associated income-probability-situation, and that “...only algebra, not human behavior, is involved in this definition."

To state this more explicitly, let X denote a simple lottery and A denote a compound lottery, $\succ$ express strict preference, and express indifference. Then the ROCL axiom says that A $\sim \mathrm{X}$ if the

probabilities in $\mathrm{X}$ are the actuarially-equivalent probabilities from $\mathrm{A}$. Thus let the initial lottery pay $\$ 10$ if a coin flip is a head and $\$ 0$ if the coin flip is a tail. Then if $\mathrm{A}$ is the compound lottery that pays double the outcome of the coin-flip lottery if a die roll is a 1 or a 2; triple the outcome of the coin-flip lottery if a die roll is a 3 or 4; and quadruple the outcome of the coin-flip lottery if a die roll is a 5 or 6 . In this case $\mathrm{X}$ would be the lottery that pays $\$ 20$ with probability $1 / 2 \times 1 / 3=1 / 6, \$ 30$ with probability $1 / 6, \$ 40$ with probability $1 / 6$, and nothing with probability $1 / 2$. Figure 1 depicts compound lottery $\mathrm{A}$ and its 
actuarially-equivalent $\mathrm{X}$ in the upper and lower panel, respectively.

The Binary ROCL axiom restricts the application of ROCL to compound binary lotteries and the actuarially-equivalent, simple, binary lottery. In the words of Selten, Sadrieh and Abbink [1999; p.211ff]

It is sufficient to assume that the following two conditions are satisfied. [...] Monotonicity. The decision maker's utility for simple binary lotteries involving the same high prize with a probability of $\mathrm{p}$ and the same low prize with the complementary probability 1-p is monotonically increasing in p. [...] Reduction of compound binary lotteries. The decision maker is indifferent between a compound binary lottery and a simple binary lottery involving the same prizes and the same probability of winning the high prize. Both postulates refer to binary lotteries only. Reduction of compound binary lotteries is a much weaker requirement than an analogous axiom for compound lotteries in general.

To use the earlier example, with the Binary ROCL axiom we would have to restrict the compound lottery A to consist of only two final prizes, rather than four prizes $(\$ 20, \$ 30, \$ 40$ or $\$ 0)$. Thus the initial stage of compound lottery A might pay 70 points if a 6-sided die roll comes up 1 or 2 or 3,30 points if the die roll comes up 4 , and 15 points if the die roll comes up 5 or 6 , and the second stage might then pay $\$ 16$ or $\$ 5$ depending on the points earned in the initial lottery. For example, if a subject earns 15 points and a 100-sided die with faces 1 though 100 comes up 15 or lower then she would earn $\$ 16$, and $\$ 5$ otherwise. There are only two final prizes to this binary compound lottery, $\$ 16$ or $\$ 5$, and the actuarially equivalent lottery $\mathrm{X}$ pays $\$ 16$ with probability $0.45(=1 / 2 \times 0.7+1 / 6 \times 0.3+1 / 3 \times 0.15)$ and $\$ 5$ with probability $0.55(=1 / 2 \times 0.3+1 / 6 \times 0.7+1 / 3 \times 0.85)$. Figure 2 depicts the compound version of this binary lottery and its actuarially equivalent in the upper and lower panel, respectively.

With objective probabilities the binary lottery procedure generates risk neutral behavior even if the decision maker violates EUT in the "probabilistically sophisticated manner" as defined by Machina and Schmeidler [1992][1995]. For example, assume that the decision maker uses a Rank-Dependent Utility model with a simple, monotonically increasing probability weighting function, such as $\mathrm{w}(\mathrm{p})=\mathrm{p}^{\gamma}$ for $\gamma \neq 1$. Then the higher prize receives decision weight $\mathrm{w}(\mathrm{p})$, where $\mathrm{p}$ is the objective probability of 
the higher prize, and the lower prize receives decision weight 1-w(p). EUT is violated in this case, but neither of the axioms needed for the binary lottery procedure to induce risk neutrality are violated. ${ }^{13}$ The application of the binary lottery procedure under non-EUT models is much more complicated if the underlying probabilities are subjective rather than objective.

\section{Experiment}

Table 1 summarizes our experimental design, and the sample size of subjects and choices in each treatment. All sessions were conducted in 2011 at the ExCEN experimental lab of Georgia State University (http://excen.gsu.edu/Laboratory.html). Subjects were recruited from a database of volunteers from classes in all undergraduate colleges at Georgia State University initiated at the beginning of the 2010-2011 academic year.

In treatment $\mathbf{A}$ we have subjects undertake one binary choice, where the one pair they face is drawn at random from a set of 24 lottery pairs shown in Table B1 of Appendix B. Figure 3 shows the interface used, showing the objective probabilities of each monetary prize.

The lottery pairs span five monetary prize amounts, $\$ 5, \$ 10, \$ 20, \$ 35$ and $\$ 70$, and five objective probabilities, $0,1 / 4,1 / 2,3 / 4$ and 1 . They are based on a subset of a battery of lottery pairs developed by Wilcox [2010] for the purpose of robust estimation of RDU models. ${ }^{14}$ These lotteries contain some pairs in which the "EUT-safe" lottery has a bigher EV than the "EUT-risky" lottery: this is designed deliberately to evaluate the extent of risk premia deriving from probability pessimism rather

${ }^{13}$ Berg, Rietz and Dickaut [2008] argue that the lottery procedure requires a model of decision making under risk that assumes linearity in probabilities. This is incorrect as a theoretical matter, if the objective is solely to induce risk neutrality. Their remarks are valid if the objective is to induce a specific risk attitude other than risk neutrality, following Berg, Daley, Dickhaut and O'Brien [1986].

${ }^{14}$ The original battery includes repetition of some choices, to help identify the "error rate" and hence the behavioral error parameter, defined later. In addition, the original battery was designed to be administered in its entirety to every subject. 
than diminishing marginal utility. None of the lottery pairs have prospects with equal EV, and the range of EV differences is wide. Each lottery in treatment A is a simple lottery, with no compounding.

In treatment A we do not have to assume that the IA applies for the payment protocol in order for observed choices to reflect risk preferences under EUT or RDU. ${ }^{15}$ In effect, it represents the behavioral Gold Standard benchmark, against which the other payment protocols are to be evaluated, following Starmer and Sugden [1991], Beattie and Loomes [1997], Cubitt, Starmer and Sugden [1998], Cox, Sadiraj and Schmidt [2011] and Harrison and Swarthout [2012]. For our purposes the critical feature of our design is that we do not test the binary lottery procedure conditional on some needlessly restrictive axiom being valid.

The standard language in the instructions for treatment A that describe the lotteries sets the stage for the variants in other treatments:

The outcome of the prospects will be determined by the draw of a random number between 1 and 100. Each number between, and including, 1 and 100 is equally likely to occur. In fact, you will be able to draw the number yourself using two 10-sided dice.

In the above example the left prospect pays five dollars $(\$ 5)$ if the number drawn is between 1 and 40 , and pays fifteen dollars (\$15) if the number is between 41 and 100 . The blue color in the pie chart corresponds to $40 \%$ of the area and illustrates the chances that the number drawn will be between 1 and 40 and your prize will be $\$ 5$. The orange area in the pie chart corresponds to $60 \%$ of the area and illustrates the chances that the number drawn will be between 41 and 100 and your prize will be $\$ 15$.

${ }^{15}$ Following Segal [1988][1990][1992], the Mixture Independence Axiom (MIA) says that the preference ordering of two simple lotteries must be the same as the actuarially-equivalent simple lottery formed by adding a common outcome in a compound lottery of each of the simple lotteries, where the common outcome has the same value and the same (compound lottery) probability. Let X, Y and Z denote simple lotteries and $\succ$ express strict preference. The MIA says that $\mathrm{X} \succ \mathrm{Y}$ iff the actuarially-equivalent simple lottery of $\alpha \mathrm{X}+(1-\alpha) \mathrm{Z}$ is strictly preferred to the actuarially-equivalent simple lottery of $\alpha \mathrm{Y}+(1-\alpha) \mathrm{Z}, \forall \alpha \in$ $(0,1)$. The verbose language used to state the axiom makes it clear that MIA embeds ROCL into the usual independence axiom construction with a common prize $\mathrm{Z}$ and a common probability $(1-\alpha)$ for that prize. When choices only involve simple lotteries, as in treatment $\mathrm{A}$, a weaker version of the independence axiom, called the Compound Independence Axiom, can be applied to justify the use of the RLIM. In general, we will be considering choices over compound lotteries when we apply the BLP, so the MIA is needed to justify the use of the RLIM when we extend treatment A to allow for several lottery choices in treatment $\mathrm{C}$. Treatment A, to repeat, does not need the RLIM. Although we say "Independence Axiom" in the text, the context should make clear which version of the axiom is involved. 
Now look at the pie in the chart on the right. It pays five dollars $(\$ 5)$ if the number drawn is between 1 and 50, ten dollars (\$10) if the number is between 51 and 90, and fifteen dollars (\$15) if the number is between 91 and 100. As with the prospect on the left, the pie slices represent the fraction of the possible numbers which yield each payoff. For example, the size of the $\$ 15$ pie slice is $10 \%$ of the total pie.

This language is changed in as simple a manner as possible to introduce the lotteries defined over points in the following treatments.

Treatment B introduces the binary lottery procedure in which the initial lottery choice is over prizes defined in points, matching the monetary prizes used in treatment A. We use the same lotteries in treatment $\mathrm{A}$ to construct the initial lotteries in treatment $\mathrm{B}$, but with the interim prizes defined in terms of points as shown in Figure 4.

We construct the lotteries in our treatment B battery by interpreting the dollar amounts as points that define the probability of getting the highest prize of $\$ 100$. For example, consider the lottery pair from treatment $\mathrm{A}$ where the left lottery is $(\$ 20,0 \% ; \$ 35,75 \% ; \$ 70,25 \%)$ and the right lottery is $(\$ 20,25 \% ; \$ 35,0 \% ; \$ 70,75 \%)$. We then construct a lottery pair that the subject sees in treatment B by defining the monetary prizes as points: so the left lottery becomes $(20$ points, $0 \% ; 35$ points, $75 \% ; 70$ points, $25 \%$ ) and the right lottery becomes (20 points, 25\%; 35 points, $0 \%$; 70 points, $75 \%$ ). The outcomes of these lotteries are points that determine the probability of winning the highest prize.

Therefore, these initial lotteries defined in terms of points are in fact binary compound lotteries in treatment $\mathrm{B}$, mapping into the two final monetary prizes of $\$ 100$ and $\$ 0 .{ }^{16}$ The left lottery is a compound lottery that gives the subject $75 \%$ chance of playing the lottery $(\$ 100,35 \% ; \$ 0,65 \%)$ and $25 \%$ probability of playing $(\$ 100,70 \% ; \$ 0,30 \%)$. Similarly, the right lottery is a compound lottery that offers the subject $25 \%$ chance of playing $(\$ 100,20 \%$; $\$ 0,80 \%)$ and $75 \%$ chance of playing $(\$ 100,70 \%$;

${ }^{16}$ To be verbose, to anticipate the extension to treatment $\mathrm{D}$, each of the lotteries in points are simple lotteries, and each of the lotteries in money are now compound lotteries. Thus the MIA would be needed to justify the RLIM in treatment D; the RLIM is not needed in treatment B. 
$\$ 0,30 \%)$. The actuarially-equivalent simple lotteries of these compound lotteries are $(\$ 100,43.75 \%$; $\$ 0$,

$56.25 \%)$ and $(\$ 100,57.50 \% ; \$ 0,42.50 \%)$, respectively, but these actuarially-equivalent simple lotteries

are obviously not presented to subjects as such.

The relevant part of the instructions mimics the information given for treatment A, but with

respect to points, and then explains how points are converted to monetary prizes:

You earn points in this task. We explain below how points are converted to cash payoffs.

The outcome of the prospects will be determined by the draw of two random numbers between 1 and 100 . The first random number drawn determines the number of points you earn in the chosen prospect, and the second random number determines whether you win the high or the low amount according to the points earned. The high amount is $\$ 100$ and the low amount is $\$ 0$. Each random number between, and including, 1 and 100 is equally likely to occur. In fact, you will be able to draw the two random numbers yourself by rolling two 10 -sided dice twice.

The payoffs in each prospect are points that give you the chance of winning the $\$ 100$ high amount. The more points you earn, the greater your chance of winning $\$ 100$. In the left prospect of the above example you earn five points (5) if the outcome of the first dice roll is between 1 and 25, twenty points (20) if the outcome of the dice roll is between 26 and 75 , and seventy points (70) if the outcome of the roll is between 76 and 100 . The blue color in the pie chart corresponds to $25 \%$ of the area and illustrates the chances that the number drawn will be between 1 and 25 and your prize will be 5 points. The orange area in the pie chart corresponds to $50 \%$ of the area and illustrates the chances that the number drawn will be between 26 and 75 and your prize will be 20 points. Finally, the green area in the pie chart corresponds to the remaining $25 \%$ of the area and illustrates that the number drawn will be between 76 and 100 and your prize is 70 points.

Now look at the pie in the chart on the right. You earn five points (5) if the first number drawn is between 1 and 50 and seventy points (70) if the number is between 51 and 100. As with the prospect on the left, the pie slices represent the fraction of the possible numbers which yield each payoff. For example, the size of the 5 points pie slice is $50 \%$ of the total pie.

Every point that you earn gives you greater chance of being paid for this task. If you earn 70 points then you have a $70 \%$ chance of being paid $\$ 100$. If you earn 20 points then you have a $20 \%$ chance of being paid $\$ 100$. After you determine the number of points that you earn by rolling the two 10-sided dice once, you will then roll the same dice for a second time to determine if you get $\$ 100$ or $\$ 0$. If your second roll is a number that is less than or equal to the number of points that you earned, you win $\$ 100$. If the second roll is a number that is greater than the number of points that you earned, you get $\$ 0$. If you do not win $\$ 100$ you receive nothing from this task, but of course you get to keep your show-up fee. 


\section{Again, the more points you earn the greater your chance of winning $\$ 100$ in this task.}

Treatment $\mathbf{C}$ extends treatment $\mathrm{A}$ by asking subjects to make $\mathrm{K} \gg 1$ binary lottery choices over prizes defined by monetary prizes and then selecting one of the $\mathrm{K}$ at random for resolution and payment. ${ }^{17}$ This is the case that is most widely used in the experimental literature, and relies on the RLIM procedure for the choice patterns to be comparable to those in treatment A. In turn, the RLIM procedure rests on the validity of the IA, as noted earlier.

Treatment $\mathbf{D}$ extends treatment $\mathbf{B}$ and applies the lottery procedure to the situation in which the subject makes $K \gg 1$ binary lottery choices over prizes defined initially by points. ${ }^{18}$ Hence it also relies on the validity of the RLIM procedure for choices in treatment $\mathrm{D}$ and treatment $\mathrm{B}$ to be the same. The test of the binary lottery procedure that is generated by comparing treatments $C$ and $D$ is therefore a joint test of the Binary ROCL axiom and the IA.

Treatment $\mathbf{E}$ extends treatment B by adding information on the expected value of each lottery in the choice display. The only change in the interface is to add the text atop each lottery shown in Figure 5. We deliberately introduce the notion of expectation using a natural frequency representation, as in the statement, "If this prospect were played 1000 times, on average the payoff would be 37.5 points." The instructions augmented those for treatment B with just this extra paragraph:

\section{Above each prospect you will be told what the average payoff would be if this prospect was played 1000 times. You will only play the prospect once if you choose it.}

No other changes in procedures were employed compared to treatment B.

Finally, treatment $\mathbf{F}$ extends treatment $\mathrm{E}$ by adding a "cheap talk" explanation as to why it might be in the best interest of the decision maker to choose lotteries so as to maximize expected

\footnotetext{
${ }^{17} \mathrm{~K}=30$ or 40 in all tasks in treatment $\mathrm{C}$. Lottery pairs were selected from a wider range than those used in treatments B and D, but only lottery pairs that match those found in treatments B and D are reported to ensure comparability.

${ }^{18} \mathrm{~K}=24$ in all tasks in treatment $\mathrm{D}$.
} 
points:

You maximize your chance of winning $\$ 100$ by choosing the prospect that gives you on average the highest number of points. However, this may not be perfectly clear, so we will now explain why this is true.

Continue with the example above, and suppose you choose the prospect on the left. You can expect to win 28.8 points on average if you played it enough times. This means that your probability of winning $\$ 100$ would be $28.8 \%$ on average. However, if you choose the prospect on the right you can expect to win more points on average: the expected number of points is 37.5 . Therefore, you can expect to win $\$ 100$ with $37.5 \%$ probability on average.

You can see in the example above that by choosing the prospect on the left you would win on average less points than in the prospect on the right. Therefore, your chances of winning $\$ 100$ in the prospect on left are lower on average than your chances of winning $\$ 100$ in the prospect on the right.

Therefore, you maximize your chances of winning $\$ 100$ by choosing the prospect that offers the highest expected number of points.

These instructions necessarily build on the notion of the expected value, so it would not be natural to try to generate a treatment with cheap talk without providing the EV information.

We acknowledge openly that these normative variants might end up working in the desired direction but for the wrong reason. Providing the EV to subjects might simply "anchor" behavior directly, and both might generate linear utility because of "demand effects." In one sense, we do not care what the explanation is, as long as the procedures reliably generate behavior consistent with linear utility functions. In another sense, we do care, because the observed behavior might not be reliable for normative evaluation of behavior. ${ }^{19}$

${ }^{19}$ The issue is subtle, but should not be glossed. It is akin to evaluating preferences revealed by choices after individuals have been exposed to advertizing. We add this rhetorical warning, since modern behaviorists are fond of casually referring to "constructed preferences" as if the concept had some operational meaning. 


\section{Results}

The basic results can be presented in terms of choice patterns that are consistent or not with the prediction that subjects will pick the lottery with the greatest EV. We then extend the analysis to allow for a cardinal measure of the extent of deviation from EV maximization, as well as structural models of behavior, to better evaluate the effect of the treatments. Evaluating choice patterns has the advantage that one can remain agnostic about the particular model of decision making under risk being used, but it has the disadvantage that one does not use all of the information in the stimuli. The information that is not used is the difference in EV between the two lotteries: intuitively, a deviation from EV maximization should be more serious if the EV difference is large than when it is minuscule. Of course, to use that information one has to make some assumptions about what determines the probability of any predicted choice.

A structural model of behavior, using Expected Utility Theory for example, allows one to use information on the size of errors from the perspective of the null hypothesis. For example, choices that are inconsistent with the null hypothesis but that involve statistically insignificant errors from the perspective of that hypothesis are not treated with the same weight as statistically significant errors. One setting in which this could arise is if we had some subjects who were approximately risk neutral over monetary prizes, and some who were decidedly risk averse. In a statistical sense, we should care more about the validity of the choices of the latter subjects: a structural model allows that, conditional of course on "the assumed structure," but the evaluation of choice patterns treats these choices equally. In addition, it is relatively easy to extend the structural model to allow for varying degrees of heterogeneity of preferences, which is an advantage for between-subject tests of the lottery procedure.

In the end, we draw essentially the same conclusions from evaluating choice patterns and structural estimates of preferences. 


\section{A. Do Subjects Pick the Lottery With the Higher Expected Value?}

The primary hypothesis is crisp: that the binary lottery procedure generates more choices that are consistent with risk neutral behavior. We calculate the EV for each lottery, and then simply tabulate how many choices were consistent with that prediction. Table 2 contains these results.

The fraction of choices consistent with risk neutrality in Table 2 starts out in the control treatment $\mathrm{A}$ at $60.0 \%$, and increases to $73.9 \%$ in treatment B. This difference is statistically significant, and in the predicted direction. A Fisher Exact test rejects the hypothesis that treatments A and B generate the same choice patterns with a (one-sided) $p$-value of 0.073 . Because the binary lottery procedure predicts the direction of differences in choices, a one-sided test is the appropriate one to use.

Turning to the comparison of choice patterns in treatments $\mathrm{C}$ and $\mathrm{D}$, one observes the same trend. The fraction of choices consistent with risk neutrality increases from $63.5 \%$ in treatment $\mathrm{C}$ increases to $68.7 \%$ in treatment D. Even though this is a smaller increment in percentage points than

for treatments $\mathrm{A}$ and $\mathrm{B}$, the sample sizes are significantly larger: by design, $\mathrm{K}$ times larger per subject. If we momentarily ignore the fact that each subject contributed several choices to these data, we can again apply a one-sided Fisher Exact test and reject the hypothesis that treatments C and D generate the same choice patterns with a $p$-value of 0.003 . However, we do need to correct for this clustering at the level of the individual, and an appropriate test statistic in this case is the Pearson $\chi^{2}$ statistic adjusted for clustering with the second-order correction of Rao and Scott [1984]. This test leads one to reject the null hypothesis with a one-sided $p$-value of 0.031 .

Treatments $\mathrm{E}$ and $\mathrm{F}$ add normative tweaks to the binary lottery procedure, to see if one can nudge the fraction of risk neutral choices even higher than in treatment B. The effects are mixed, although parallel to the effect of treatment B compared to treatment A. Adding information on the EV does not make much of a difference to the "vanilla" binary lottery procedure, nor does adding "cheap talk." Of course, this is completely consistent with the hypothesis that the subjects that moved towards 
risk neutral choices already understood how to guesstimate or calculate the $\mathrm{EV}$, and that this would be how they maximize their chance of winning the $\$ 100$. Pooling treatments $B, E$ and $F$ together, and comparing to treatment $\mathrm{A}$, we can reject the null hypothesis of no change compared to treatment $\mathrm{A}$ using a Fisher Exact test and a $p$-value of 0.036.

\section{B. Effect on Expected V alue Maximization}

As noted earlier, Selten, Sadrieh and Abbink [1999] developed a statistic to test the strength of the deviation from risk neutrality and EV maximization. For all choices by a subject, it takes the difference between the maximum EV that could have been earned and the EV that was chosen. A risk neutral subject would have a statistic value of zero, and a risk averse subject would generally have a positive statistic value. So the null hypothesis is that the lottery procedure moves the value of this statistic to zero, or at least in that direction, compared to the treatment with direct monetary prizes. This statistic aggregates all choices by a given subject, so can be calculated in a similar manner for all of our treatments. ${ }^{20}$ Statistical significance is then tested by conducting non-parametric tests of the hypothesis that the distribution of these statistics is the same across treatments.

The average values for this statistic for treatments $\mathrm{A}, \mathrm{B}, \mathrm{C}, \mathrm{D}, \mathrm{E}$ and $\mathrm{F}$ are $\$ 2.57,1.87$ points, $\$ 2.79,2.31$ points, 1.29 points and 1.28 points, respectively. So there is movement in the predicted direction for the binary lottery treatments B, E and F when compared to treatment A, and for treatment D compared to treatment C. For the treatments with only one choice task, we find overall that the statistic moves in the right direction, and significantly. Pooling over treatments $\mathrm{B}, \mathrm{E}$ and $\mathrm{F}$, the

${ }^{20}$ In our design it just so happens that expected value is the same as expected points in treatments B, $\mathrm{E}$ and $\mathrm{F}$. This is due to the particular transformation we used to convert a given dollar-lottery into a pointslottery: a low prize of $\$ 0$, a high prize of $\$ 100$, and a total of 100 points. This equivalence need not hold in other settings in which one might apply the lottery procedure. This equivalence in our design also facilitates the pooling of choices across treatments in the econometric comparisons of behavior presented below. 
average statistic is 1.57 points, compared to $\$ 2.57$ for treatment $A$. This difference in means is statistically significant in a $t$-test with a one-sided alternative hypothesis test and a $p$-value of 0.066 , assuming unequal variances. Using the Wilcoxon-Mann-Whitney two-sample test of rank sums, we also conclude that the distributions are different, with a one-sided $p$-value of only 0.025 . For treatments $\mathrm{C}$ and $\mathrm{D}$ we find that the statistic again moves in the right direction and that the differences are statistically significant, using either the rank sum test of the distributions or the $t$-test and $p$-values less than 0.01 .

\section{Effect on Estimated Risk Preferences}

Appendix $\mathrm{C}$ outlines a simple specification of a structural model to estimate risk preferences, assuming Expected Utility Theory (EUT). The specification is by now quite standard, and is explained in detail by Harrison and Rutström [2008]. We generally assume a Constant Relative Risk Aversion (CRRA) utility function with coefficient $r$, such that $r=0$ denotes risk neutrality and $r>0$ denotes risk aversion under EUT.

The estimates are striking. Initially assume that differences in risk preferences were randomized across treatments, so that the average effect of the treatment can be reliably estimated without controlling for heterogeneity of preferences. Under treatment A we estimate $r$ to be 0.981 , with a 95\% confidence interval between 0.54 and 1.42 , and the effect of treatment B is to lower that by 0.912 such that the estimated $\mathrm{r}$ for treatment B is only 0.069 with a $95 \%$ confidence interval between -0.45 and 0.59. The $p$-value on the test that the treatment $\mathrm{B}$ risk aversion coefficient is different from zero is 0.793, so we cannot reject the hypothesis that the lottery procedure worked as advertized.

The effect of the lottery procedure is not so sharp when we consider the designs of treatments $\mathrm{C}$ and D that employ the RLIM payment protocol. In this case the risk aversion coefficient $\mathrm{r}$ for treatment $C$ is estimated to be 0.725 with a $95 \%$ confidence interval between 0.66 and 0.79 , and the 
effect of the lottery procedure is to lower that by 0.45 . Hence the estimated risk aversion coefficient under treatment $\mathrm{D}$ is 0.161 , with a $95 \%$ confidence interval between 0.15 and 0.17 , and a $p$-value on the one-sided hypothesis of risk neutrality of only 0.032 . So we observe clear movement in the direction of risk neutrality, but not the attainment of risk neutrality. The estimated effect of the lottery procedure, 0.45, has a $95 \%$ confidence interval between -0.75 and -0.15 .

We can extend these structural models to provide some allowance for subject heterogeneity. Because the data for each subject in treatments $\mathrm{A}$ and $\mathrm{B}$ consist of just one observation, one loses degrees of freedom rapidly with too many demographic characteristics. For example, in samples of 55, how many Asian females are Seniors? Larger samples would obviously mitigate this issue, but for present purposes a simpler solution is to merge in data from comparable tasks and samples drawn at random from the same population. In this case we were able to use data for treatment A using lotteries that use the same prizes and probabilities, but in different combinations than the 24 we focus on in the comparisons of choice patterns. ${ }^{21}$ This increases the sample size for estimation from 55 to 149 under treatment A. ${ }^{22}$ This is not appropriate when one is comparing choice patterns, since the stimuli are different in nature, but is appropriate when one is estimating risk preferences.

Allowing for subject heterogeneity confirms our qualitative conclusions from assuming that randomization to treatment led to the same distribution of preferences across treatments. Detailed estimation results are provided in Appendix C, and control for a number of binary characteristics: blp is 1 for choices in treatment B or treatment D; female is 1 for women, and 0 otherwise; sophomore and senior are 1 for whether that was the current stage of undergraduate education at GSU, and 0 otherwise; and asian and white are 1 based on self-reported ethnic status, and 0 otherwise.

\footnotetext{
${ }^{21}$ The additional lotteries are documented in Harrison and Swarthout [2012].

22 The fraction of choices consistent with risk neutrality drops slightly, from $60.0 \%$ to $58.4 \%$, with the enhanced sample.
} 
Controlling for observable characteristics in this manner, for treatments A and B we estimate the coefficient on the lottery procedure dummy to be -0.70 , with a $p$-value of 0.034 , and the constant term for treatment $A$ to be 0.74 with a $p$-value of less than 0.001 . The net effect, the estimated coefficient for treatment B after controlling for the demographic covariates, is -0.042 with a $p$-value of 0.90, so we again cannot reject the null hypothesis that the lottery procedure induces risk neutral behavior. Predicting risk attitudes using these estimates, the average $\mathrm{r}$ for treatment $\mathrm{A}$ is 0.63 , and for treatment B is -0.077 . Figure 6 displays kernel densities of the predicted risk attitudes over all subjects, demonstrating the dramatic effect of the binary lottery procedure. These conclusions stay the same if we pool in the choices from treatments $\mathrm{E}$ and F; again, the normative variants in the binary lottery procedure displays and instructions do not, by themselves, make much of a difference.

For treatments $\mathrm{C}$ and $\mathrm{D}$ we estimate the effect of the lottery procedure on the risk aversion coefficient to be -0.48 with a $p$-value of 0.003 , compared to the constant term of 0.67 with a $p$-value also less than 0.001 . So the net effect, demographics aside, is for the lottery procedure to lower the estimated risk aversion to 0.20 with a $95 \%$ confidence interval between -0.14 and 0.53 and a $p$-value of 0.25. Figure 7 shows the distribution of estimated risk attitudes from predicted values that account for heterogeneity of preferences. The average predicted risk aversion in treatment $\mathrm{C}$ is 0.73 and in treatment $\mathrm{D}$ is 0.26 . The effect is not as complete as estimated for treatments $\mathrm{A}$ and $\mathrm{B}$, but clearly in the predicted direction.

\section{Conclusions}

Our results clearly show that the binary lottery procedure works for samples of university level students in the simplest possible environment, where we can be certain that there are no contaminating factors and the theory to be tested requires no auxiliary assumptions. This does not automatically make the lottery procedure useful for samples from different populations. Nor does it automatically mean 
that it applies in all settings, since it is often the "contaminating factor," such as strategic behavior, that is precisely the domain where we would like it to work. But there are many circumstances where one can implement the environment considered here.

We find that the lottery procedure works robustly to induce risk neutrality when subjects are given one task, and that it works well when subjects are given more than one task. The extent to which the procedure works is certainly diminished as one moves from environments with one task to environments with many tasks, but there is always a statistically significant reduction in risk aversion, and in neither case can one reject the hypothesis that the procedure induced risk neutral behavior as advertized.

Our results should encourage efforts to actively try to find procedures that can identify and increase the sub-sample of subjects for whom the lottery procedure does induce linear utility, and the populations for which it appears to work reliably. ${ }^{23}$ Even with a given population, it is logically possible that the procedure "works as advertized" for some subjects, just not all, or even for a majority. There can still be value in identifying those subjects. Moreover, if simple treatments can increase that fraction, or just improve the statistical identification of that fraction, then we might discover a "best practice" variant of the basic lottery procedure. Although the variants we considered in our design did not increase the faction of risk neutral choices significantly, they could play a behavioral role in other populations.

${ }^{23}$ For example, Hossain and Okui [2011] evaluate the procedure in the context of eliciting the probability of a binary event. 


\section{Table 1: Experimental Design}

All choices drawn from the same battery of 24 lottery pairs at random.

All subjects receive a $\$ 7.50$ show-up fee.

Subjects were told that there would be no other salient task in the experiment.

\begin{tabular}{|l|c|}
\hline Treatment & $\begin{array}{c}\text { Subjects } \\
\text { (Choices) }\end{array}$ \\
\hline A. Monetary prizes with only one binary choice (Figure 3) & 55 \\
B. Binary lottery points with only one binary choice (Figure 4) & $(55)$ \\
C. Monetary prizes with one binary choice out of K»1 selected for & 69 \\
payment (Figure 3) & $(69)$ \\
D. Binary lottery points with one binary choice out of K»1 selected for & 208 \\
payment (Figure 4) & $(2104)$ \\
E. Binary lottery points with only one binary choice and with EV & 39 \\
information provided for each lottery (Figure 5) & $(936)$ \\
F. Binary lottery points with only one binary choice and with EV & 34 \\
information provided for each lottery (Figure 5), as well as “cheap \\
talk" instructions
\end{tabular}


Figure 1: Graphical Representation of Compound Lottery A and its Actuarially-Equivalent Lottery X

\section{Compound Lottery}

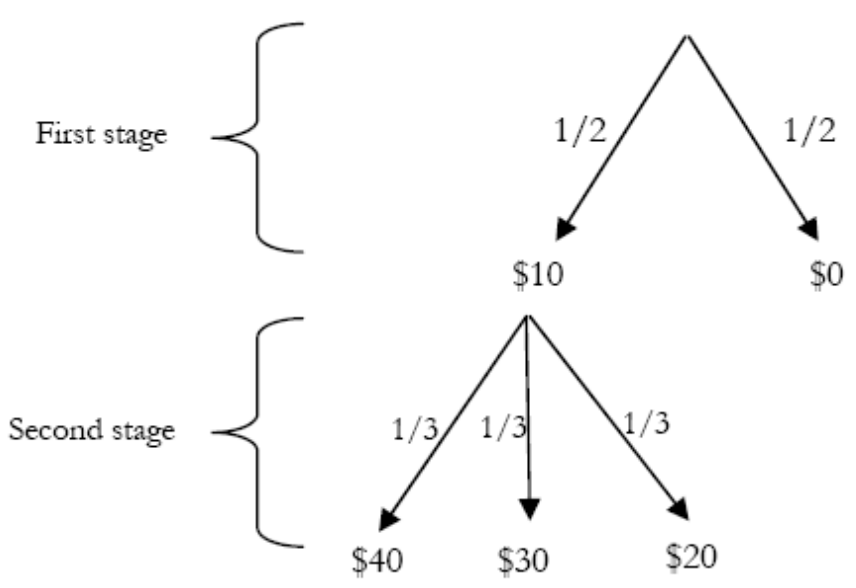

Actuarially-Equivalent Lottery

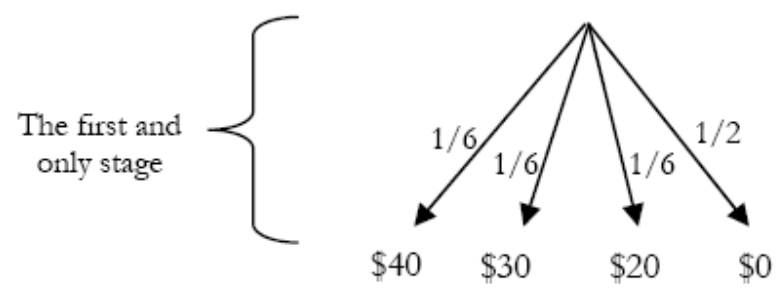


Figure 2: Graphical Representation of the Compound Version of a Binary Lottery and its Actuarially-Equivalent Lottery

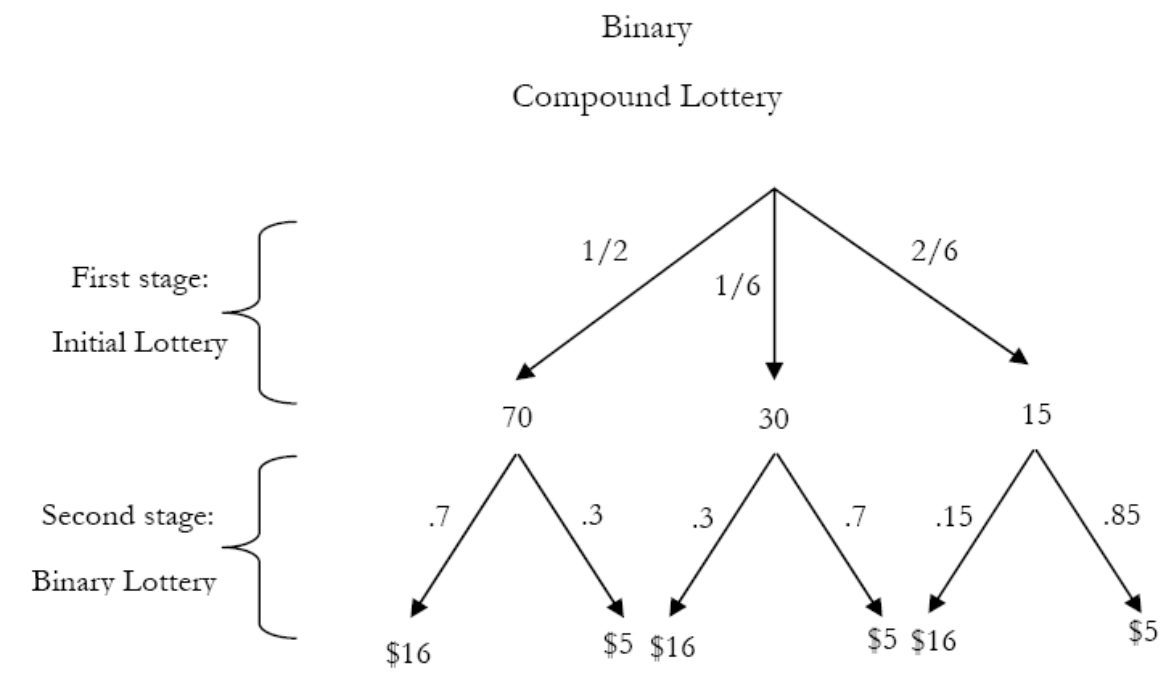

Actuarially-Equivalent Lottery

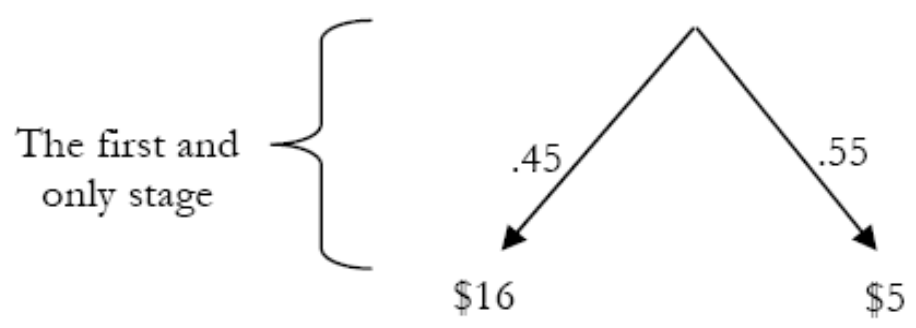


Figure 3: Default Binary Choice Interface

Left

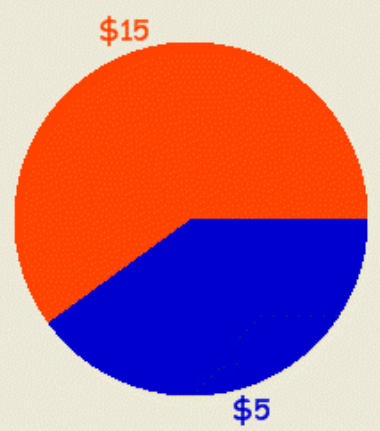

Chance of winning $\$ 5$ is $40 \%$

Chance of winning $\$ 15$ is $60 \%$

Select Left
Right

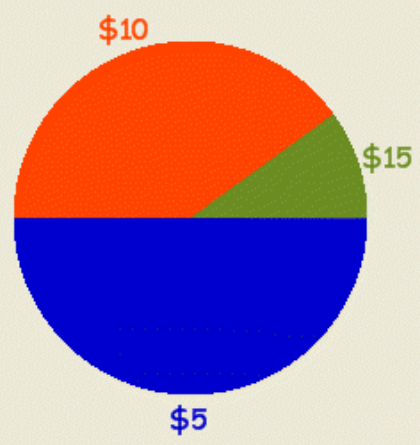

Chance of winning $\$ 5$ is $50 \%$

Chance of winning $\$ 10$ is $40 \%$

Chance of vinning $\$ 15$ is $10 \%$

Select Right 
Figure 4: Choice Interface for Points

\section{More points increase your chance of winning $\$ 100$}

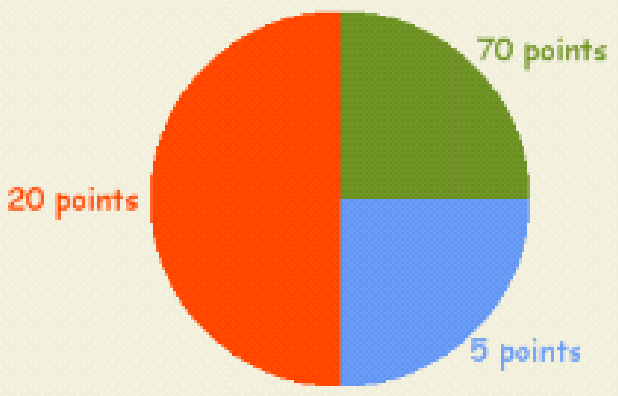

Chance of winning 5 points is $25 \%$

Chance of winning 20 points is $50 \%$

Chance of winning 70 points is $25 \%$

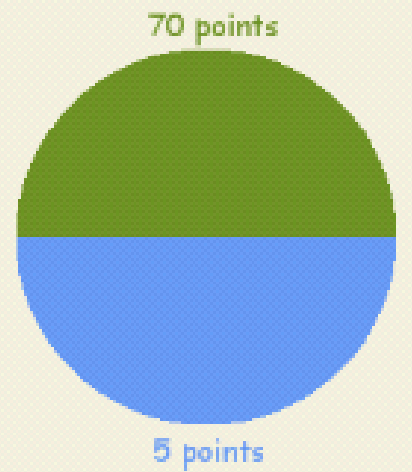

Chance of vimning 5 points is $50 \%$

Chonce of winning 70 points is $50 \%$

Select Left

Select Right 
Figure 5: Choice Interface for Points with Expected Value Information

\section{More points increase your chance of winning $\$ 100$}

If this prospect were played 1000 times, on average the payoff would be 28.8 points

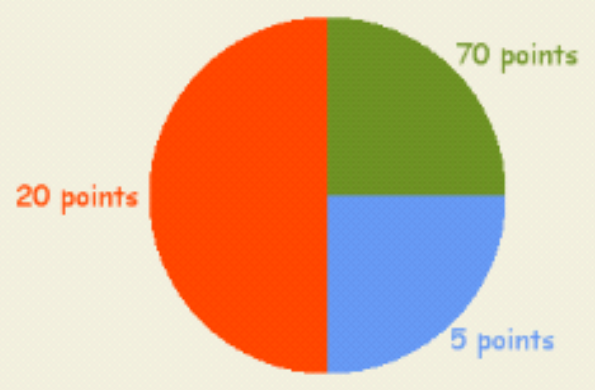

Chance of winning 5 points is $25 \%$

Chance of winning 20 points is $50 \%$

Chance of winning 70 points is $25 \%$
If this prospect were played 1000 times, on average the payoff would be 37.5 points

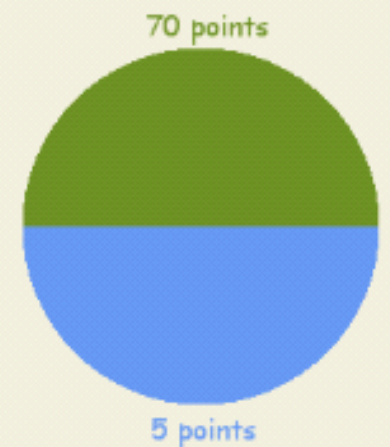

Chance of winning 5 points is $50 \%$

Chance of winning 70 points is $50 \%$

Select Left

Select Right 
Table 2: Observed Choice Patterns

\begin{tabular}{|c|c|c|c|}
\hline Treatment & $\begin{array}{l}\text { Risk neutral } \\
\text { choices }\end{array}$ & $\begin{array}{l}\text { Other } \\
\text { choices }\end{array}$ & $\begin{array}{l}\text { All } \\
\text { choices }\end{array}$ \\
\hline A. Monetary prizes with one choice (Figure 3) & $\begin{array}{c}33 \\
(60 \%)\end{array}$ & $\begin{array}{c}22 \\
(40 \%)\end{array}$ & $\begin{array}{c}55 \\
(100 \%)\end{array}$ \\
\hline B. Binary lottery points with one choice (Figure 4) & $\begin{array}{c}51 \\
(74 \%)\end{array}$ & $\begin{array}{c}18 \\
(26 \%)\end{array}$ & $\begin{array}{c}69 \\
(100 \%)\end{array}$ \\
\hline C. Monetary prizes with K»1 choices (Figure 3) & $\begin{array}{l}1,336 \\
(63 \%)\end{array}$ & $\begin{array}{c}768 \\
(37 \%)\end{array}$ & $\begin{array}{c}2,104 \\
(100 \%)\end{array}$ \\
\hline D. Binary lottery points with $K \gg 1$ choices (Figure 4 ) & $\begin{array}{c}643 \\
(69 \%)\end{array}$ & $\begin{array}{c}293 \\
(31 \%)\end{array}$ & $\begin{array}{c}936 \\
(100 \%)\end{array}$ \\
\hline $\begin{array}{l}\text { E. Binary lottery points with one choice and EV } \\
\text { information (Figure 5) }\end{array}$ & $\begin{array}{c}24 \\
(71 \%)\end{array}$ & $\begin{array}{c}10 \\
(29 \%)\end{array}$ & $\begin{array}{c}34 \\
(100 \%)\end{array}$ \\
\hline $\begin{array}{l}\text { F. Binary lottery points with one choice and EV } \\
\text { information (Figure 5), plus "cheap talk" } \\
\text { instructions }\end{array}$ & $\begin{array}{c}30 \\
(79 \%)\end{array}$ & $\begin{array}{c}8 \\
(21 \%)\end{array}$ & $\begin{array}{c}38 \\
(100 \%)\end{array}$ \\
\hline
\end{tabular}


Figure 6: Estimated Risk Attitudes in Treatments A and B

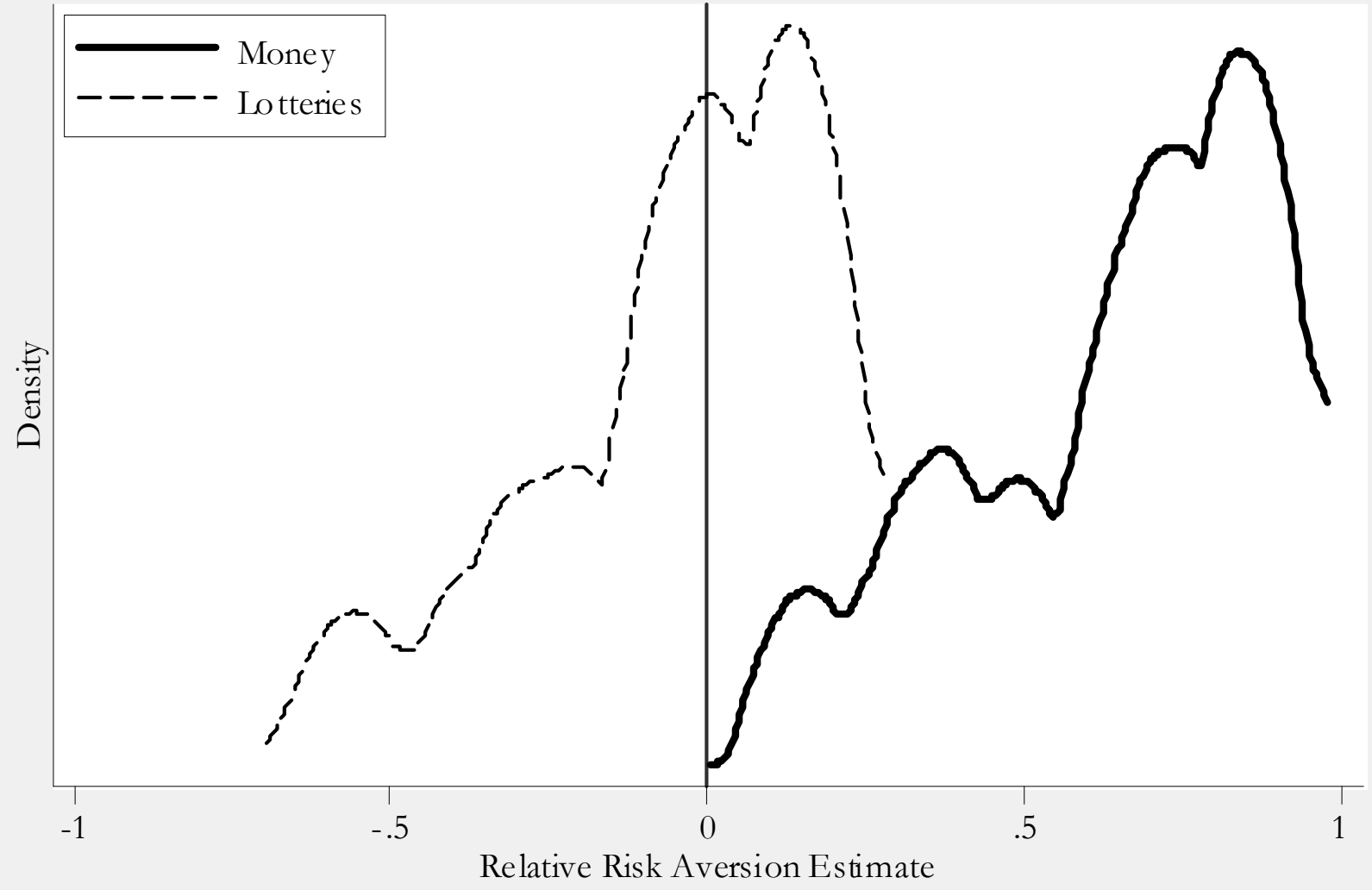


Figure 7: Estimated Risk Attitudes in Treatments C and D

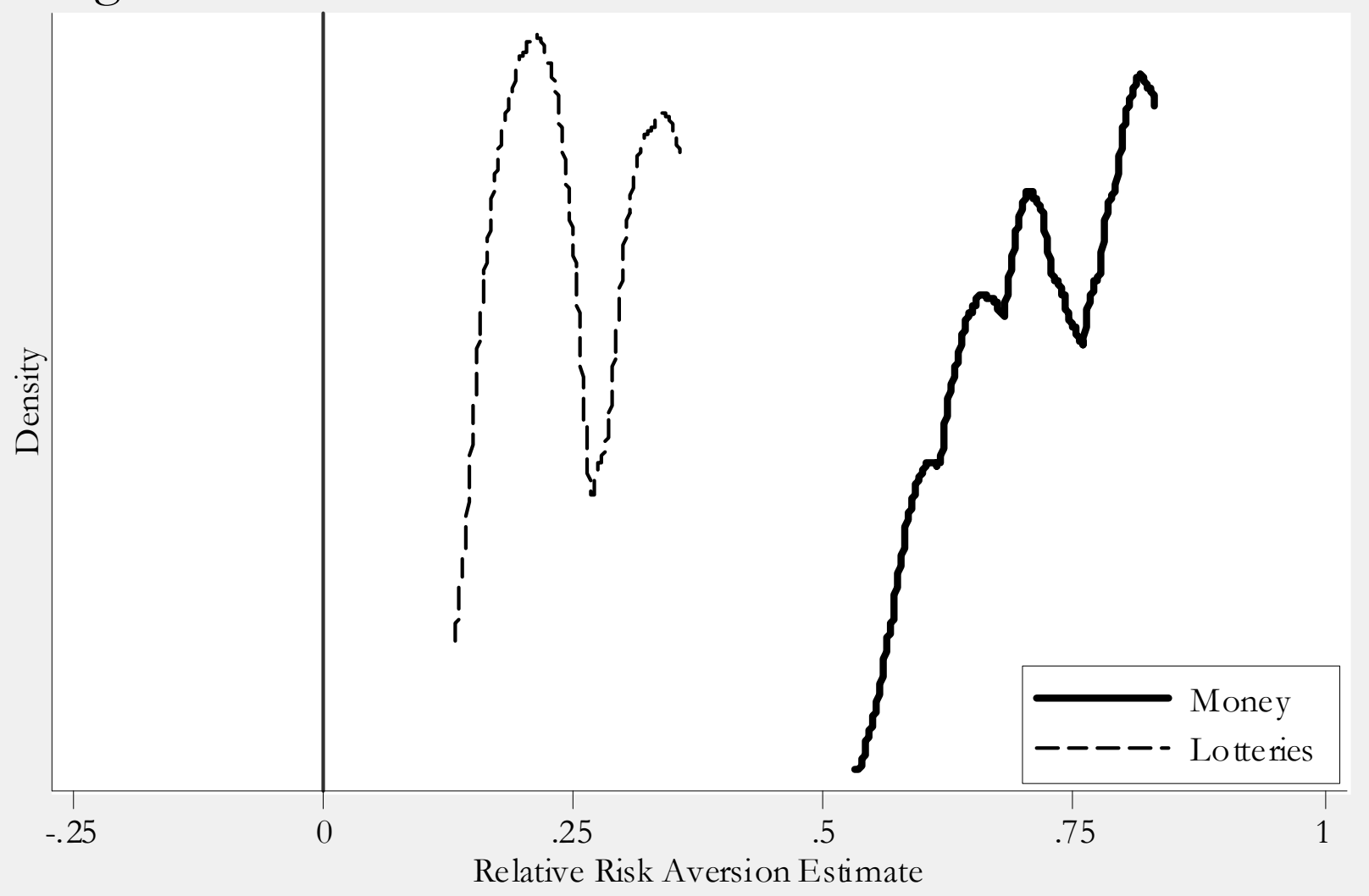




\section{References}

Beattie, J., and Loomes, Graham, “The Impact of Incentives Upon Risky Choice Experiments,” Journal of Risk and Uncertainty, 14, 1997, 149-162.

Berg, Joyce E.; Daley, Lane A.; Dickhaut, John W.; and O’Brien, John R., "Controlling Preferences for Lotteries on Units of Experimental Exchange," Quarterly Journal of Economics, 101, May 1986, 281-306.

Berg, Joyce E.; Rietz, Thomas A., and Dickhaut, John W., "On the Performance of the Lottery Procedure for Controlling Risk Preferences," in C.R. Plott and V.L. Smith (eds.), Handbook of Experimental Economics Results (New York: Elsevier Press, 2008).

Braunstein, Yale M., and Schotter, Andrew, "Labor Market Search: An Experimental Study," Economic Inquiry, 20, January 1982, 133-144.

Cooper, Russell; DeJong, Douglas V.; Forsythe, Robert, and Ross, Thomas W., "Communication in the Battle of the Sexes Game: Some Experimental Results," Rand Journal of Economics, 20, Winter 1989, pp. 568-587.

Cooper, Russell; DeJong, Douglas V.; Forsythe, Robert, and Ross, Thomas W., "Selection Criteria in Coordination Games: Some Experimental Results," American Economic Review, 80, March 1990, pp. 218-233.

Cooper, Russell; DeJong, Douglas V.; Forsythe, Robert, and Ross, Thomas W., "Communication in Coordination Games,” Quarterly Journal of Economics, 107, May 1992, 739-771.

Cooper, Russell; DeJong, Douglas V.; Forsythe, Robert, and Ross, Thomas W., "Forward Induction in the Battle-of-Sexes Games," American Economic Review, 83(5), December 1993, 1303-1316.

Cox, James C., and Oaxaca, Ronald L., "Inducing Risk-Neutral Preferences: Further Analysis of the Data," Journal of Risk and Uncertainty, 11, 1995, 65-79.

Cox, James C.; Sadiraj, Vjollca, and Schmidt, Ulrich, "Paradoxes and Mechanisms for Choice under Risk," Working Paper 2011-12, Center for the Economic Analysis of Risk, Robinson College of Business, Georgia State University, 2011.

Cox, James C.; Smith, Vernon L.; and Walker, James M., "Experimental Development of Sealed-Bid Auction Theory: Calibrating Controls for Risk Aversion," American Economic Review (Papers \& Proceedings), 75, May 1985, 160-165.

Cubitt, Robin P.; Starmer, Chris, and Sugden, Robert, "On the Validity of the Random Lottery Incentive System,” Experimental Economics, 1(2), 1998, 115-131.

Harrison, Glenn W., "Theory and Misbehavior of First-Price Auctions," American Economic Review, 79, September 1989, 749-762. 
Harrison, Glenn W., "Theory and Misbehavior of First-Price Auctions: Reply," American Economic Review, 82, December 1992, 1426-1443.

Harrison, Glenn W., "Expected Utility Theory and the Experimentalists," Empirical Economics, 19(2), 1994, 223-253; reprinted in J.D. Hey (ed.), Experimental Economics (Heidelberg: Physica-Verlag, 1994).

Harrison, Glenn W., and McCabe, Kevin, "Testing Noncooperative Bargaining Theory in Experiments," in R.M. Isaac (ed.), Research in Experimental Economics (Greenwich: JAI Press, Volume 5, 1992).

Harrison, Glenn W., and McCabe, Kevin A., "Expectations and Fairness in a Simple Bargaining Experiment," International Journal of Game Theory, 25(3), 1996, 303-327.

Harrison, Glenn W., and Rutström, E. Elisabet, "Trade Wars, Trade Negotiations, and Applied Game Theory," Economic Journal, 101, May 1991, 420-435.

Harrison, Glenn W., and Rutström, E. Elisabet, "Risk Aversion in the Laboratory," in J.C. Cox and G.W. Harrison (eds.), Risk Aversion in Experiments (Bingley, UK: Emerald, Research in Experimental Economics, Volume 12, 2008).

Harrison, Glenn W., and Swarthout, J. Todd, “Independence and the Bipolar Behaviorist," Working Paper 2012-01, Center for the Economic Analysis of Risk, Robinson College of Business, Georgia State University, 2012.

Holt, Charles A., and Laury, Susan K., "Risk Aversion and Incentive Effects," American Economic Review, 92(5), December 2002, 1644-1655.

Hossain, Tanjim, and Okui, Ryo, “The Binarized Scoring Rule,” Working Paper, University of Toronto, August 2011.

Machina, Mark J., and Schmeidler, David, "A More Robust Definition of Subjective Probability," Econometrica, 60(4), July 1992, 745-780.

Machina, Mark J., and Schmeidler, David, "Bayes without Bernoulli: Simple Conditions for Probabilistically Sophisticated Choice," Journal of Economic Theory, 67, 1995, 106-128.

Ochs, Jack, and Roth, Alvin E., "An Experimental Study of Sequential Bargaining," American Economic Review, 79(3), June 1989, 355-384.

Rao, J. N. K., and Scott, A. J., "On Chi-squared Tests for Multiway Contingency Tables with Cell Proportions Estimated from Survey Data," Annals of Statistics, 12, 1984, 46-60.

Rietz, Thomas A., "Implementing and Testing Risk Preference Induction Mechanisms in Experimental Sealed Bid Auctions," Journal of Risk and Uncertainty, 7, 1993, 199-213. 
Roth, Alvin E., and Malouf, Michael W. K., "Game-Theoretic Models and the Role of Information in Bargaining," Psychological Review, 86, 1979, 574-594.

Samuelson, Paul A., "Probability, Utility, and the Independence Axiom," Econometrica, 20, 1952, 670678.

Savage, Leonard J., The Foundations of Statistics (New York: John Wiley, 1954).

Savage, Leonard J., The Foundations of Statistics (New York: Dover Publications, 1972; Second Edition).

Segal, Uzi, "Does the Preference Reversal Phenomenon Necessarily Contradict the Independence Axiom?” American Economic Review, 78(1), March 1988, 233-236.

Segal, Uzi, "Two-Stage Lotteries Without the Reduction Axiom," Econometrica, 58(2), March 1990, 349377.

Segal, Uzi, “The Independence Axiom Versus the Reduction Axiom: Must We Have Both?” in W. Edwards (ed.), Utility Theories: Measurements and Applications (Boston: Kluwer Academic Publishers, 1992).

Selten, Reinhard; Sadrieh, Abdolkarim, and Abbink, Klaus, "Money Does Not Induce Risk Neutral Behavior, but Binary Lotteries Do even Worse," Theory and Decision, 46(3), June 1999, 211-249.

Smith, Cedric A.B., "Consistency in Statistical Inference and Decision," Journal of the Royal Statistical Society, 23, 1961, 1-25.

Starmer, Chris, and Sugden, Robert, "Does the Random-Lottery Incentive System Elicit True Preferences? An Experimental Investigation," American Economic Review, 81, 1991, 971-978.

Walker, James M.; Smith, Vernon L., and Cox, James C., "Inducing Risk Neutral Preferences: An Examination in a Controlled Market Environment," Journal of Risk and Uncertainty, 3, 1990, 5-24.

Wilcox, Nathaniel T., "A Comparison of Three Probabilistic Models of Binary Discrete Choice Under Risk,” Working Paper, Economic Science Institute, Chapman University, March 2010. 


\section{Appendix A: Instructions (NOT FOR PUBLICATION)}

\section{Treatment $A$}

\section{Choices Over Risky Prospects}

This is a task where you will choose between prospects with varying prizes and chances of winning. You will be presented with one pair of prospects where you will choose one of them. You should choose the prospect you prefer to play. You will actually get the chance to play the prospect you choose, and you will be paid according to the outcome of that prospect, so you should think carefully about which prospect you prefer.

Here is an example of what the computer display of a pair of prospects will look like.

Left

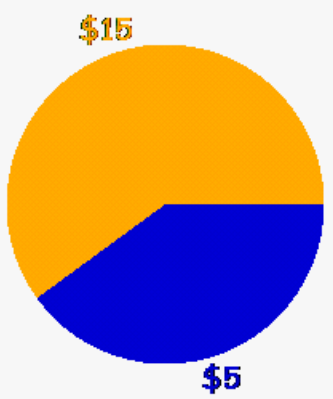

Chance of winning $\$ 5$ is $40 \%$

Chance of winning $\$ 15$ is $60 \%$
Right

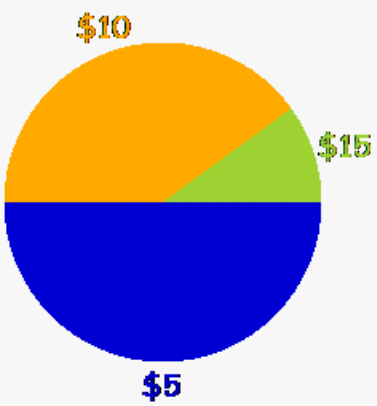

Chance of winning $\$ 5$ is $50 \%$

Chance of winning $\$ 10$ is $40 \%$

Chance of winning $\$ 15$ is $10 \%$

Select Left

Select Right

The outcome of the prospects will be determined by the draw of a random number between 1 and 100. Each number between, and including, 1 and 100 is equally likely to occur. In fact, you will be able to draw the number yourself using two 10-sided dice.

In the above example the left prospect pays five dollars $(\$ 5)$ if the number drawn is between 1 and 40, and pays fifteen dollars (\$15) if the number is between 41 and 100 . The blue color in the pie 
chart corresponds to $40 \%$ of the area and illustrates the chances that the number drawn will be between 1 and 40 and your prize will be $\$ 5$. The orange area in the pie chart corresponds to $60 \%$ of the area and illustrates the chances that the number drawn will be between 41 and 100 and your prize will be $\$ 15$.

Now look at the pie in the chart on the right. It pays five dollars $(\$ 5)$ if the number drawn is between 1 and 50, ten dollars (\$10) if the number is between 51 and 90, and fifteen dollars $(\$ 15)$ if the number is between 91 and 100. As with the prospect on the left, the pie slices represent the fraction of the possible numbers which yield each payoff. For example, the size of the $\$ 15$ pie slice is $10 \%$ of the total pie.

The pair of prospects you choose from is shown on a screen on the computer. On that screen, you should indicate which prospect you prefer to play by clicking on one of the buttons beneath the prospects.

After you have made your choice, raise your hand and an experimenter will come over. It is certain that your one choice will be played out for real. You will roll the two ten-sided dice to determine the outcome of the prospect you chose.

For instance, suppose you picked the prospect on the left in the above example. If the random number was 37 , you would win $\$ 5$; if it was 93 , you would get $\$ 15$. If you picked the prospect on the right and drew the number 37, you would get $\$ 5$; if it was 93 , you would get $\$ 15$.

Therefore, your payoff is determined by two things:

- $\quad$ by which prospect you selected, the left or the right; and

- by the outcome of that prospect when you roll the two 10-sided dice.

Which prospects you prefer is a matter of personal taste. The people next to you may be presented with a different prospect, and may have different preferences, so their responses should not matter to you. Please work silently, and make your choices by thinking carefully about the prospect you are presented with.

All payoffs are in cash, and are in addition to the $\$ 7.50$ show-up fee that you receive just for being here. The only other task today is for you to answer some demographic questions. Your answers to those questions will not affect your payoffs.

\section{Treatment B}

\section{Choices Over Risky Prospects}

This is a task where you will choose between prospects with varying chances of winning either a high amount or a low amount. You will be presented with one pair of prospects where you will choose one of them. You should choose the prospect you prefer to play. You will actually get the chance to play the prospect you choose, and you will be paid according to the final outcome of that prospect, so you should think carefully about which prospect you prefer.

Here is an example of what the computer display of a pair of prospects will look like. 
You earn points in this task. We explain below how points are converted to cash payoffs.

\section{More points increase your chance of winning $\$ 100$}

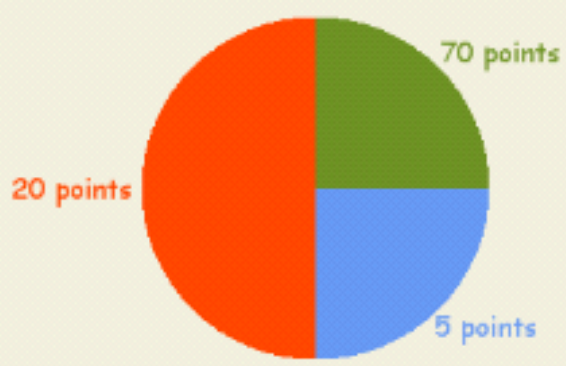

Chance of winning 5 points is $25 \%$

Chance of winning 20 points is $50 \%$

Chance of winning 70 points is $25 \%$

Select Left

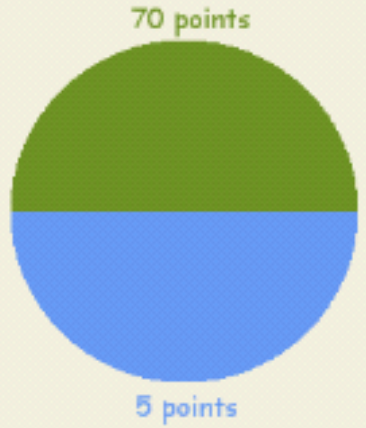

Chance of usinning 5 points is $50 \%$

Chonce of winning 70 points is $50 \%$

The outcome of the prospects will be determined by the draw of two random numbers between 1 and 100. The first random number drawn determines the number of points you earn in the chosen prospect, and the second random number determines whether you win the high or the low amount according to the points earned. The high amount is $\$ 100$ and the low amount is $\$ 0$. Each random number between, and including, 1 and 100 is equally likely to occur. In fact, you will be able to draw the two random numbers yourself by rolling two 10-sided dice twice.

The payoffs in each prospect are points that give you the chance of winning the $\$ 100$ high amount. The more points you earn, the greater your chance of winning $\$ 100$. In the left prospect of the above example you earn five points (5) if the outcome of the first dice roll is between 1 and 25 , twenty points (20) if the outcome of the dice roll is between 26 and 75, and seventy points (70) if the outcome of the roll is between 76 and 100 . The blue color in the pie chart corresponds to $25 \%$ of the area and illustrates the chances that the number drawn will be between 1 and 25 and your prize will be 5 points. The orange area in the pie chart corresponds to $50 \%$ of the area and illustrates the chances that the number drawn will be between 26 and 75 and your prize will be 20 points. Finally, the green area in the pie chart corresponds to the remaining $25 \%$ of the area and illustrates that the number drawn will be 
between 76 and 100 and your prize is 70 points.

Now look at the pie in the chart on the right. You earn five points (5) if the first number drawn is between 1 and 50 and seventy points (70) if the number is between 51 and 100. As with the prospect on the left, the pie slices represent the fraction of the possible numbers which yield each payoff. For example, the size of the 5 points pie slice is $50 \%$ of the total pie.

Every point that you earn gives you greater chance of being paid for this task. If you earn 70 points then you have a $70 \%$ chance of being paid $\$ 100$. If you earn 20 points then you have a $20 \%$ chance of being paid $\$ 100$. After you determine the number of points that you earn by rolling the two 10 -sided dice once, you will then roll the same dice for a second time to determine if you get $\$ 100$ or $\$ 0$. If your second roll is a number that is less than or equal to the number of points that you earned, you win $\$ 100$. If the second roll is a number that is greater than the number of points that you earned, you get $\$ 0$. If you do not win $\$ 100$ you receive nothing from this task, but of course you get to keep your show-up fee. Again, the more points you earn the greater your chance of winning $\$ 100$ in this task.

The pair of prospects you choose from is shown on a screen on the computer. On that screen, you should indicate which prospect you prefer to play by clicking on one of the buttons beneath the prospects.

After you have made your choice, raise your hand and an experimenter will come over. It is certain that your one choice will be played out for real. You will then roll the two ten-sided dice twice: first to determine the number of points you win, and then to determine whether you win $\$ 100$ or $\$ 0$ according to the points earned.

For instance, suppose you picked the prospect on the left in the above example. If the outcome of the first dice roll was 17 , you would win 5 points. This means that your chance of winning $\$ 100$ is $5 \%$. Now, if the outcome of the second dice roll was 1 , which is less than the number of points you earned, you would win $\$ 100$. If the second roll was 75 instead, you would earn nothing because the outcome of this roll is greater than the number of points you earned.

Here is another example. If you picked the prospect on the right and the outcome of the first dice roll was 60 , then you would earn 70 points. This means that your probability of winning $\$ 100$ would be $70 \%$. If the outcome of the second dice roll was 1 , then you would earn $\$ 100$; but if the second roll was 75 instead you would earn $\$ 0$ in this task.

Therefore, your payoff is determined by three things:

- $\quad$ the prospect you selected, the left or the right;

- the outcome of the first roll of the two 10-sided dice which determines the number of points your earn in your chosen prospect; and

- the outcome of the second roll of the two 10-sided dice which will be compared with your earned points to determine whether you earn $\$ 0$ or $\$ 100$.

Which prospect you prefer is a matter of personal taste. The people next to you may be presented with a different pair of prospects, so their responses should not matter to you. Please work silently, and 
make your choices by thinking carefully about the pair of prospects you are presented with.

All payoffs are in cash, and are in addition to the $\$ 7.50$ show-up fee that you receive just for being here. The only other task today is for you to answer some demographic questions. Your answers to those questions will not affect your payoffs.

\section{Treatment $C$}

\section{Choices Over Risky Prospects}

This is a task where you will choose between prospects with varying prizes and chances of winning. You will be presented with a series of pairs of prospects where you will choose one of them. There are 30 pairs in the series. For each pair of prospects, you should choose the prospect you prefer to play. You will actually get the chance to play one of the prospects you choose, and you will be paid according to the outcome of that prospect, so you should think carefully about which prospect you prefer.

Here is an example of what the computer display of such a pair of prospects will look like.

\section{SAME DISPLAY AS FOR TREATMENT A}

The outcome of the prospects will be determined by the draw of a random number between 1 and 100. Each number between, and including, 1 and 100 is equally likely to occur. In fact, you will be able to draw the number yourself using two 10-sided dice.

In the above example the left prospect pays five dollars (\$5) if the number drawn is between 1 and 40, and pays fifteen dollars (\$15) if the number is between 41 and 100. The blue color in the pie chart corresponds to $40 \%$ of the area and illustrates the chances that the number drawn will be between 1 and 40 and your prize will be $\$ 5$. The orange area in the pie chart corresponds to $60 \%$ of the area and illustrates the chances that the number drawn will be between 41 and 100 and your prize will be $\$ 15$.

Now look at the pie in the chart on the right. It pays five dollars $(\$ 5)$ if the number drawn is between 1 and 50, ten dollars (\$10) if the number is between 51 and 90, and fifteen dollars $(\$ 15)$ if the number is between 91 and 100. As with the prospect on the left, the pie slices represent the fraction of the possible numbers which yield each payoff. For example, the size of the $\$ 15$ pie slice is $10 \%$ of the total pie.

Each pair of prospects is shown on a separate screen on the computer. On each screen, you should indicate which prospect you prefer to play by clicking on one of the buttons beneath the prospects.

After you have worked through all of the pairs of prospects, raise your hand and an experimenter will come over. You will then roll a 30-sided die to determine which pair of prospects will be played out. Since there is a chance that any of your 30 choices could be played out for real, you should approach each pair of prospects as if it is the one that you will play out. Finally, you will roll the two ten-sided dice to determine the outcome of the prospect you chose. 
For instance, suppose you picked the prospect on the left in the above example. If the random number was 37 , you would win $\$ 5$; if it was 93 , you would get $\$ 15$. If you picked the prospect on the right and drew the number 37 , you would get $\$ 5$; if it was 93 , you would get $\$ 15$.

Therefore, your payoff is determined by three things:

- $\quad$ by which prospect you selected, the left or the right, for each of these 30 pairs;

- by which prospect pair is chosen to be played out in the series of 30 such pairs using the 30-sided die; and

- $\quad$ by the outcome of that prospect when you roll the two 10-sided dice.

Which prospects you prefer is a matter of personal taste. The people next to you may be presented with different prospects, and may have different preferences, so their responses should not matter to you. Please work silently, and make your choices by thinking carefully about each prospect.

All payoffs are in cash, and are in addition to the $\$ 7.50$ show-up fee that you receive just for being here. The only other task today is for you to answer some demographic questions. Your answers to those questions will not affect your payoffs.

\section{Treatment D}

\section{Choices Over Risky Prospects}

This is a task where you will choose between prospects with varying chances of winning either a high amount or a low amount. You will be presented with a series of pairs of prospects where you will choose one of them. There are 24 pairs in the series. For each pair of prospects, you should choose the prospect you prefer to play. You will actually get the chance to play one of the prospects you choose, and you will be paid according to the final outcome of that prospect, so you should think carefully about which prospect you prefer.

Here is an example of what the computer display of a pair of prospects will look like.

\section{SAME DISPLAY AS FOR TREATMENT B}

You earn points in this task. We explain below how points are converted to cash payoffs.

The outcome of the prospects will be determined by the draw of two random numbers between 1 and 100. The first random number drawn determines the number of points you earn in the chosen prospect, and the second random number determines whether you win the high or the low amount according to the points earned. The high amount is $\$ 100$ and the low amount is $\$ 0$. Each random number between, and including, 1 and 100 is equally likely to occur. In fact, you will be able to draw the two random numbers yourself by rolling two 10 -sided dice twice.

The payoffs in each prospect are points that give you the chance of winning the $\$ 100$ high amount. The more points you earn, the greater your chance of winning $\$ 100$. In the left prospect of the above example you earn five points (5) if the outcome of the first dice roll is between 1 and 25, twenty points (20) if the outcome of the dice roll is between 26 and 75, and seventy points (70) if the outcome 
of the roll is between 76 and 100 . The blue color in the pie chart corresponds to $25 \%$ of the area and illustrates the chances that the number drawn will be between 1 and 25 and your prize will be 5 points. The orange area in the pie chart corresponds to $50 \%$ of the area and illustrates the chances that the number drawn will be between 26 and 75 and your prize will be 20 points. Finally, the green area in the pie chart corresponds to the remaining $25 \%$ of the area and illustrates that the number drawn will be between 76 and 100 and your prize is 70 points.

Now look at the pie in the chart on the right. You earn five points (5) if the first number drawn is between 1 and 50 and seventy points (70) if the number is between 51 and 100. As with the prospect on the left, the pie slices represent the fraction of the possible numbers which yield each payoff. For example, the size of the 5 points pie slice is $50 \%$ of the total pie.

Every point that you earn gives you greater chance of being paid for this task. If you earn 70 points then you have a $70 \%$ chance of being paid $\$ 100$. If you earn 20 points then you have a $20 \%$ chance of being paid $\$ 100$. After you determine the number of points that you earn by rolling the two 10 -sided dice once, you will then roll the same dice for a second time to determine if you get $\$ 100$ or $\$ 0$. If your second roll is a number that is less or equal to the number of points that you earned, you win $\$ 100$. If the second roll is a number that is greater than the number of points that you earned, you get $\$ 0$. If you do not win $\$ 100$ you receive nothing from this task, but of course you get to keep your show-up fee. Again, the more points you earn the greater your chance of winning $\$ 100$ in this task.

Each pair of prospects is shown on a separate screen on the computer. On each screen, you should indicate which prospect you prefer to play by clicking on one of the buttons beneath the prospects.

After you have worked through all of the pairs of prospects, raise your hand and an experimenter will come over. You will then roll a 30-sided die until a number between 1 and 24 comes up to determine which pair of prospects will be played out for real. Since there is a chance that any of your 24 choices could be played out for real, you should approach each pair of prospects as if it is the one that you will play out. Finally, you will then roll the two ten-sided dice twice: first to determine the number of points you win, and then to determine whether you win $\$ 100$ or $\$ 0$ according to the points earned.

For instance, suppose you picked the prospect on the left in the above example. If the outcome of the first dice roll was 17 , you would win 5 points. This means that your chance of winning $\$ 100$ is $5 \%$. Now, if the outcome of the second dice roll was 1 , which is less than the number of points you earned, you would win $\$ 100$. If the second roll was 75 instead, you would earn nothing because the outcome of this roll is greater than the number of points you earned.

Here is another example. If you picked the prospect on the right and the outcome of the first dice roll was 60 , then you would earn 70 points. This means that your probability of winning $\$ 100$ would be $70 \%$. If the outcome of the second dice roll was 1 , then you would earn $\$ 100$; but if the second roll was 75 instead you would earn $\$ 0$ in this task.

Therefore, your payoff is determined by four things:

- $\quad$ the prospect you selected, the left or the right, for each of these 24 pairs; 
- the prospect pair that is chosen to be played out in the series of 24 such pairs using the 30 -sided die;

- the outcome of the first roll of the two 10-sided dice which determines the number of points your earn in your chosen prospect; and

- the outcome of the second roll of the two 10-sided dice which will be compared with your earned points to determine whether you earn $\$ 0$ or $\$ 100$.

Which prospect you prefer is a matter of personal taste. The people next to you may be presented with different prospects, so their responses should not matter to you. Please work silently, and make your choices by thinking carefully about the pair of prospects you are presented with.

All payoffs are in cash, and are in addition to the $\$ 7.50$ show-up fee that you receive just for being here. The only other task today is for you to answer some demographic questions. Your answers to those questions will not affect your payoffs.

Treatment E

SAME INSTRUCTIONS AS FOR TREATMENT B, WITH ADDITIONS PRESENTED IN THE TEXT AND USING DISPLAY IN FIGURE 5.

\section{Treatment F}

SAME INSTRUCTIONS AS FOR TREATMENT E, WITH ADDITIONS PRESENTED IN THE TEXT AND USING DISPLAY IN FIGURE 5. 
Appendix B: Parameters of Experiment

Table B1: Battery of Monetary Lotteries

\begin{tabular}{|c|c|c|c|c|c|c|c|c|c|c|c|c|}
\hline \multirow[b]{2}{*}{ Pair } & \multicolumn{4}{|c|}{ Prizes } & \multicolumn{3}{|c|}{ "Safe" Lottery Probabilities } & \multicolumn{3}{|c|}{ "Risky" Lottery Probabilities } & \multirow[b]{2}{*}{ EV Safe } & \multirow[b]{2}{*}{ EV Risky } \\
\hline & Context & Low & Middle & High & Low & Middle & High & Low & Middle & High & & \\
\hline 1 & 5 & $\$ 5$ & $\$ 20$ & $\$ 70$ & 0 & 0.75 & 0.25 & 0.25 & 0 & 0.75 & $\$ 32.50$ & $\$ 53.75$ \\
\hline 2 & 5 & $\$ 5$ & $\$ 20$ & $\$ 70$ & 0.25 & 0.5 & 0.25 & 0.5 & 0 & 0.5 & $\$ 28.75$ & $\$ 37.50$ \\
\hline 3 & 5 & $\$ 5$ & $\$ 20$ & $\$ 70$ & 0 & 0.5 & 0.5 & 0.25 & 0 & 0.75 & $\$ 45.00$ & $\$ 53.75$ \\
\hline 4 & 6 & $\$ 5$ & $\$ 35$ & $\$ 70$ & 0 & 1 & 0 & 0.25 & 0 & 0.75 & $\$ 35.00$ & $\$ 53.75$ \\
\hline 5 & 6 & $\$ 5$ & $\$ 35$ & $\$ 70$ & 0.25 & 0.75 & 0 & 0.5 & 0 & 0.5 & $\$ 27.50$ & $\$ 37.50$ \\
\hline 6 & 6 & $\$ 5$ & $\$ 35$ & $\$ 70$ & 0 & 0.75 & 0.25 & 0.25 & 0 & 0.75 & $\$ 43.75$ & $\$ 53.75$ \\
\hline 7 & 6 & $\$ 5$ & $\$ 35$ & $\$ 70$ & 0 & 0.5 & 0.5 & 0.25 & 0 & 0.75 & $\$ 52.50$ & $\$ 53.75$ \\
\hline 8 & 6 & $\$ 5$ & $\$ 35$ & $\$ 70$ & 0 & 0.75 & 0.25 & 0.5 & 0 & 0.5 & $\$ 43.75$ & $\$ 37.50$ \\
\hline 9 & 9 & $\$ 10$ & $\$ 35$ & $\$ 70$ & 0 & 1 & 0 & 0.25 & 0 & 0.75 & $\$ 35.00$ & $\$ 55.00$ \\
\hline 10 & 9 & $\$ 10$ & $\$ 35$ & $\$ 70$ & 0.25 & 0.75 & 0 & 0.5 & 0 & 0.5 & $\$ 28.75$ & $\$ 40.00$ \\
\hline 11 & 9 & $\$ 10$ & $\$ 35$ & $\$ 70$ & 0 & 0.5 & 0.5 & 0.25 & 0 & 0.75 & $\$ 52.50$ & $\$ 55.00$ \\
\hline 12 & 9 & $\$ 10$ & $\$ 35$ & $\$ 70$ & 0 & 0.75 & 0.25 & 0.5 & 0 & 0.5 & $\$ 43.75$ & $\$ 40.00$ \\
\hline 13 & 10 & $\$ 20$ & $\$ 35$ & $\$ 70$ & 0 & 1 & 0 & 0.25 & 0 & 0.75 & $\$ 35.00$ & $\$ 57.50$ \\
\hline 14 & 10 & $\$ 20$ & $\$ 35$ & $\$ 70$ & 0.25 & 0.75 & 0 & 0.5 & 0 & 0.5 & $\$ 31.25$ & $\$ 45.00$ \\
\hline 15 & 10 & $\$ 20$ & $\$ 35$ & $\$ 70$ & 0 & 0.75 & 0.25 & 0.25 & 0 & 0.75 & $\$ 43.75$ & $\$ 57.50$ \\
\hline 16 & 10 & $\$ 20$ & $\$ 35$ & $\$ 70$ & 0 & 1 & 0 & 0.5 & 0 & 0.5 & $\$ 35.00$ & $\$ 45.00$ \\
\hline 17 & 10 & $\$ 20$ & $\$ 35$ & $\$ 70$ & 0.5 & 0.5 & 0 & 0.75 & 0 & 0.25 & $\$ 27.50$ & $\$ 32.50$ \\
\hline 18 & 10 & $\$ 20$ & $\$ 35$ & $\$ 70$ & 0 & 1 & 0 & 0.25 & 0.5 & 0.25 & $\$ 35.00$ & $\$ 40.00$ \\
\hline 19 & 10 & $\$ 20$ & $\$ 35$ & $\$ 70$ & 0.25 & 0.5 & 0.25 & 0.5 & 0 & 0.5 & $\$ 40.00$ & $\$ 45.00$ \\
\hline 20 & 10 & $\$ 20$ & $\$ 35$ & $\$ 70$ & 0 & 0.5 & 0.5 & 0.25 & 0 & 0.75 & $\$ 52.50$ & $\$ 57.50$ \\
\hline 21 & 10 & $\$ 20$ & $\$ 35$ & $\$ 70$ & 0 & 1 & 0 & 0.5 & 0.25 & 0.25 & $\$ 35.00$ & $\$ 36.25$ \\
\hline 22 & 10 & $\$ 20$ & $\$ 35$ & $\$ 70$ & 0.25 & 0.75 & 0 & 0.75 & 0 & 0.25 & $\$ 31.25$ & $\$ 32.50$ \\
\hline 23 & 10 & $\$ 20$ & $\$ 35$ & $\$ 70$ & 0 & 0.75 & 0.25 & 0.5 & 0 & 0.5 & $\$ 43.75$ & $\$ 45.00$ \\
\hline 24 & 10 & $\$ 20$ & $\$ 35$ & $\$ 70$ & 0 & 1 & 0 & 0.75 & 0 & 0.25 & $\$ 35.00$ & $\$ 32.50$ \\
\hline
\end{tabular}


Table B2: Battery of Binary Lotteries

\begin{tabular}{|c|c|c|c|c|c|c|c|c|c|c|c|c|c|c|c|c|c|c|c|c|c|c|c|}
\hline \multirow[b]{3}{*}{ Pair } & \multirow{2}{*}{\multicolumn{2}{|c|}{ Final Prizes }} & \multirow{2}{*}{\multicolumn{3}{|c|}{$\begin{array}{c}\text { Prizes in Points } \\
\text { in the Initial Lotteries }\end{array}$}} & \multicolumn{8}{|c|}{ Left Lottery } & \multicolumn{8}{|c|}{ Right Lottery } & \multirow{3}{*}{$\begin{array}{l}\text { EV } \\
\text { Left }\end{array}$} & \multirow{3}{*}{$\begin{array}{c}\text { EV } \\
\text { Right }\end{array}$} \\
\hline & & & & & & \multicolumn{3}{|c|}{$\begin{array}{r}\text { Initial Lottery } \\
\text { Probabilities }\end{array}$} & \multicolumn{3}{|c|}{$\begin{array}{c}\text { Second Lottery } \\
\text { Probability of Highest Prize }\end{array}$} & \multicolumn{2}{|c|}{$\begin{array}{l}\text { Actuarially-Equivalent } \\
\text { Lottery Probabilities } \\
\text { of Final Prizes }\end{array}$} & \multicolumn{3}{|c|}{$\begin{array}{l}\text { Initial Lottery } \\
\text { Probabilities }\end{array}$} & \multicolumn{3}{|c|}{$\begin{array}{c}\text { Second Lottery } \\
\text { Probability of Highest Prize }\end{array}$} & \multicolumn{2}{|c|}{$\begin{array}{c}\text { Actuarially-Equivalent } \\
\text { Lottery Probabilities } \\
\text { of Final Prizes }\end{array}$} & & \\
\hline & Lowest & Highest & Low & Middle & High & Low & Middle & High & Low & Middle & High & Lowest & Highest & Low & Middle & High & Low & Middle & High & Lowest & Highest & & \\
\hline 1 & $\$ 0$ & $\$ 100$ & 5 & 20 & 70 & 0 & 0.75 & 0.25 & 0.05 & 0.2 & 0.7 & 0.675 & 0.325 & 0.25 & 0 & 0.75 & 0.05 & 0.2 & 0.7 & 0.463 & 0.538 & $\$ 32.50$ & $\$ 53.7$. \\
\hline 2 & $\$ 0$ & $\$ 100$ & 5 & 20 & 70 & 0.25 & 0.5 & 0.25 & 0.05 & 0.2 & 0.7 & 0.713 & 0.288 & 0.5 & 0 & 0.5 & 0.05 & 0.2 & 0.7 & 0.625 & 0.375 & $\$ 28.75$ & $\$ 37.50$ \\
\hline 3 & $\$ 0$ & $\$ 100$ & 5 & 20 & 70 & 0 & 0.5 & 0.5 & 0.05 & 0.2 & 0.7 & 0.550 & 0.450 & 0.25 & 0 & 0.75 & 0.05 & 0.2 & 0.7 & 0.463 & 0.538 & $\$ 45.00$ & $\$ 53.75$ \\
\hline 4 & $\$ 0$ & $\$ 100$ & 5 & 35 & 70 & 0 & 1 & 0 & 0.05 & 0.35 & 0.7 & 0.65 & 0.35 & 0.25 & 0 & 0.75 & 0.05 & 0.35 & 0.7 & 0.463 & 0.538 & $\$ 35.00$ & $\$ 53.73$ \\
\hline 5 & $\$ 0$ & $\$ 100$ & 5 & 35 & 70 & 0.25 & 0.75 & 0 & 0.05 & 0.35 & 0.7 & 0.725 & 0.275 & 0.5 & 0 & 0.5 & 0.05 & 0.35 & 0.7 & 0.625 & 0.375 & $\$ 27.50$ & $\$ 37.50$ \\
\hline 6 & $\$ 0$ & $\$ 100$ & 5 & 35 & 70 & 0 & 0.75 & 0.25 & 0.05 & 0.35 & 0.7 & 0.563 & 0.438 & 0.25 & 0 & 0.75 & 0.05 & 0.35 & 0.7 & 0.463 & 0.538 & $\$ 43.75$ & $\$ 53.7$ \\
\hline 7 & $\$ 0$ & $\$ 100$ & 5 & 35 & 70 & 0 & 0.5 & 0.5 & 0.05 & 0.35 & 0.7 & 0.475 & 0.525 & 0.25 & 0 & 0.75 & 0.05 & 0.35 & 0.7 & 0.463 & 0.538 & $\$ 52.50$ & $\$ 53.7$ \\
\hline 8 & $\$ 0$ & $\$ 100$ & 5 & 35 & 70 & 0 & 0.75 & 0.25 & 0.05 & 0.35 & 0.7 & 0.563 & 0.438 & 0.5 & 0 & 0.5 & 0.05 & 0.35 & 0.7 & 0.625 & 0.375 & $\$ 43.75$ & $\$ 37.50$ \\
\hline 9 & $\$ 0$ & $\$ 100$ & 10 & 35 & 70 & 0 & 1 & 0 & 0.1 & 0.35 & 0.7 & 0.65 & 0.35 & 0.25 & 0 & 0.75 & 0.1 & 0.35 & 0.7 & 0.45 & 0.55 & $\$ 35.00$ & $\$ 55.00$ \\
\hline 10 & $\$ 0$ & $\$ 100$ & 10 & 35 & 70 & 0.25 & 0.75 & 0 & 0.1 & 0.35 & 0.7 & 0.713 & 0.288 & 0.5 & 0 & 0.5 & 0.1 & 0.35 & 0.7 & 0.600 & 0.400 & $\$ 28.75$ & $\$ 40.00$ \\
\hline 11 & $\$ 0$ & $\$ 100$ & 10 & 35 & 70 & 0 & 0.5 & 0.5 & 0.1 & 0.35 & 0.7 & 0.475 & 0.525 & 0.25 & 0 & 0.75 & 0.1 & 0.35 & 0.7 & 0.450 & 0.550 & $\$ 52.50$ & $\$ 55.00$ \\
\hline 12 & $\$ 0$ & $\$ 100$ & 10 & 35 & 70 & 0 & 0.75 & 0.25 & 0.1 & 0.35 & 0.7 & 0.563 & 0.438 & 0.5 & 0 & 0.5 & 0.1 & 0.35 & 0.7 & 0.600 & 0.400 & $\$ 43.75$ & $\$ 40.00$ \\
\hline 13 & $\$ 0$ & $\$ 100$ & 20 & 35 & 70 & 0 & 1 & 0 & 0.2 & 0.35 & 0.7 & 0.65 & 0.35 & 0.25 & 0 & 0.75 & 0.2 & 0.35 & 0.7 & 0.425 & 0.575 & $\$ 35.00$ & $\$ 57.50$ \\
\hline 14 & $\$ 0$ & $\$ 100$ & 20 & 35 & 70 & 0.25 & 0.75 & 0 & 0.2 & 0.35 & 0.7 & 0.688 & 0.313 & 0.5 & 0 & 0.5 & 0.2 & 0.35 & 0.7 & 0.550 & 0.450 & $\$ 31.25$ & $\$ 45.00$ \\
\hline 15 & $\$ 0$ & $\$ 100$ & 20 & 35 & 70 & 0 & 0.75 & 0.25 & 0.2 & 0.35 & 0.7 & 0.563 & 0.438 & 0.25 & 0 & 0.75 & 0.2 & 0.35 & 0.7 & 0.425 & 0.575 & $\$ 43.75$ & $\$ 57.50$ \\
\hline 16 & $\$ 0$ & $\$ 100$ & 20 & 35 & 70 & 0 & 1 & 0 & 0.2 & 0.35 & 0.7 & 0.650 & 0.350 & 0.5 & 0 & 0.5 & 0.2 & 0.35 & 0.7 & 0.550 & 0.450 & $\$ 35.00$ & $\$ 45.00$ \\
\hline 17 & $\$ 0$ & $\$ 100$ & 20 & 35 & 70 & 0.5 & 0.5 & 0 & 0.2 & 0.35 & 0.7 & 0.725 & 0.275 & 0.75 & 0 & 0.25 & 0.2 & 0.35 & 0.7 & 0.675 & 0.325 & $\$ 27.50$ & $\$ 32.50$ \\
\hline 18 & $\$ 0$ & $\$ 100$ & 20 & 35 & 70 & 0 & 1 & 0 & 0.2 & 0.35 & 0.7 & 0.650 & 0.350 & 0.25 & 0.5 & 0.25 & 0.2 & 0.35 & 0.7 & 0.600 & 0.400 & $\$ 35.00$ & $\$ 40.00$ \\
\hline 19 & $\$ 0$ & $\$ 100$ & 20 & 35 & 70 & 0.25 & 0.5 & 0.25 & 0.2 & 0.35 & 0.7 & 0.600 & 0.400 & 0.5 & 0 & 0.5 & 0.2 & 0.35 & 0.7 & 0.550 & 0.45 & $\$ 40.00$ & $\$ 45.00$ \\
\hline 20 & $\$ 0$ & $\$ 100$ & 20 & 35 & 70 & 0 & 0.5 & 0.5 & 0.2 & 0.35 & 0.7 & 0.475 & 0.525 & 0.25 & 0 & 0.75 & 0.2 & 0.35 & 0.7 & 0.425 & 0.575 & $\$ 52.50$ & $\$ 57.50$ \\
\hline 21 & $\$ 0$ & $\$ 100$ & 20 & 35 & 70 & 0 & 1 & 0 & 0.2 & 0.35 & 0.7 & 0.650 & 0.350 & 0.5 & 0.25 & 0.25 & 0.2 & 0.35 & 0.7 & 0.638 & 0.363 & $\$ 35.00$ & $\$ 36.25$ \\
\hline 22 & $\$ 0$ & $\$ 100$ & 20 & 35 & 70 & 0.25 & 0.75 & 0 & 0.2 & 0.35 & 0.7 & 0.688 & 0.313 & 0.75 & 0 & 0.25 & 0.2 & 0.35 & 0.7 & 0.675 & 0.325 & $\$ 31.25$ & $\$ 32.50$ \\
\hline 23 & $\$ 0$ & $\$ 100$ & 20 & 35 & 70 & 0 & 0.75 & 0.25 & 0.2 & 0.35 & 0.7 & 0.563 & 0.438 & 0.5 & 0 & 0.5 & 0.2 & 0.35 & 0.7 & 0.550 & 0.450 & $\$ 43.75$ & $\$ 45.00$ \\
\hline 24 & $\$ 0$ & $\$ 100$ & 20 & 35 & 70 & 0 & 1 & 0 & 0.2 & 0.35 & 0.7 & 0.650 & 0.350 & 0.75 & 0 & 0.25 & 0.2 & 0.35 & 0.7 & 0.675 & 0.325 & $\$ 35.00$ & $\$ 32.50$ \\
\hline
\end{tabular}




\section{Appendix C: Structural Estimation of Risk Preferences (NOT FOR PUBLICATION)}

Assume that utility of income is defined by

$$
\mathrm{U}(\mathrm{x})=\mathrm{x}^{(1-\mathrm{r})} /(1-\mathrm{r})
$$

where $\mathrm{x}$ is the lottery prize and $\mathrm{r} \neq 1$ is a parameter to be estimated. For $\mathrm{r}=1$ assume $\mathrm{U}(\mathrm{x})=\ln (\mathrm{x})$ if needed. Thus $r$ is the coefficient of CRRA: $r=0$ corresponds to risk neutrality, $r<0$ to risk loving, and $r>0$ to risk aversion. Let there be J possible outcomes in a lottery. Under EUT the probabilities for each outcome $\mathrm{x}_{\mathfrak{j}}, \mathrm{p}\left(\mathrm{x}_{\mathrm{j}}\right)$, are those that are induced by the experimenter, so expected utility is simply the probability weighted utility of each outcome in each lottery i:

$$
\mathrm{EU}_{\mathrm{i}}=\sum_{\mathrm{j}=1, \mathrm{~J}}\left[\mathrm{p}\left(\mathrm{x}_{\mathrm{j}}\right) \times \mathrm{U}\left(\mathrm{x}_{\mathrm{j}}\right)\right] .
$$

The EU for each lottery pair is calculated for a candidate estimate of $r$, and the index

$$
\nabla \mathrm{EU}=\mathrm{EU}_{\mathrm{R}}-\mathrm{EU}_{\mathrm{L}}
$$

calculated, where $\mathrm{EU}_{\mathrm{L}}$ is the "left" lottery and $\mathrm{EU}_{\mathrm{R}}$ is the "right" lottery as presented to subjects. This latent index, based on latent preferences, is then linked to observed choices using a standard cumulative normal distribution function $\Phi(\nabla E U)$. This "probit" function takes any argument between $\pm \infty$ and transforms it into a number between 0 and 1 . Thus we have the probit link function,

$$
\operatorname{prob}(\text { choose lottery } \mathrm{R})=\Phi(\nabla \mathrm{EU})
$$

Even though this "link function" is common in econometrics texts, it is worth noting explicitly and understanding. It forms the critical statistical link between observed binary choices, the latent structure generating the index $\nabla \mathrm{EU}$, and the probability of that index being observed. The index defined by (C3) is linked to the observed choices by specifying that the R lottery is chosen when $\Phi(\nabla E U)>1 / 2$, which is implied by (C4).

Thus the likelihood of the observed responses, conditional on the EUT and CRRA specifications being true, depends on the estimates of $r$ given the above statistical specification and the observed choices. The "statistical specification" here includes assuming some functional form for the 
cumulative density function (CDF). The conditional log-likelihood is then

$$
\ln \mathrm{L}(\mathrm{r} ; \mathrm{y}, \mathbf{X})=\sum_{\mathrm{i}}\left[\left(\ln \Phi(\nabla \mathrm{EU}) \times \mathbf{I}\left(\mathrm{y}_{\mathrm{i}}=1\right)\right)+\left(\ln (1-\Phi(\nabla \mathrm{EU})) \times \mathbf{I}\left(\mathrm{y}_{\mathrm{i}}=-1\right)\right)\right]
$$

where $\mathbf{I}(\cdot)$ is the indicator function, $\mathrm{y}_{\mathrm{i}}=1(-1)$ denotes the choice of the right (left) lottery in risk aversion task $\mathrm{i}$, and $\mathbf{X}$ is a vector of individual characteristics reflecting age, sex, race, and so on.

Harrison and Rutström [2008; Appendix F] review procedures that can be used to estimate structural models of this kind, as well as more complex non-EUT models. The goal is to illustrate how researches can write explicit maximum likelihood (ML) routines that are specific to different structural choice models. It is a simple matter to correct for multiple responses from the same subject (“clustering"), as needed.

It is also simple matter to generalize the ML analysis to allow the core parameter $r$ to be a linear function of observable characteristics of the individual or task. We extend the model to be $r=r_{0}+$ $\mathrm{R} \times \mathbf{X}$, where $\mathrm{r}_{0}$ is a fixed parameter and $\mathrm{R}$ is a vector of effects associated with each characteristic in the variable vector $\mathbf{X}$. In effect the unconditional model assumes $r=r_{0}$ and just estimates $r_{0}$. This extension significantly enhances the attraction of structural ML estimation, particularly for responses pooled over different subjects and treatments, since one can condition estimates on observable characteristics of the task or subject.

An important extension of the core model is to allow for subjects to make some behavioral errors. The notion of error is one that has already been encountered in the form of the statistical assumption that the probability of choosing a lottery is not 1 when the EU of that lottery exceeds the EU of the other lottery. This assumption is clear in the use of a non-degenerate link function between the latent index $\nabla \mathrm{EU}$ and the probability of picking one or other lottery; in the case of the normal $\mathrm{CDF}$, this link function is $\Phi(\nabla \mathrm{EU})$. If there were no errors from the perspective of EUT, this function would be a step function: zero for all values of $\nabla \mathrm{EU}<0$, anywhere between 0 and 1 for $\nabla \mathrm{EU}=0$, and 1 for all values of $\nabla E U>0$. 
We employ the error specification originally due to Fechner and popularized by Hey and Orme [1994]. This error specification posits the latent index

$$
\nabla \mathrm{EU}=\left(\mathrm{EU}_{\mathrm{R}}-\mathrm{EU}_{\mathrm{L}}\right) / \mu
$$

instead of (C3), where $\mu$ is a structural "noise parameter" used to allow some errors from the perspective of the deterministic EUT model. This is just one of several different types of error story that could be used, and Wilcox [2008] provides a masterful review of the implications of the alternatives. ${ }^{24}$ As $\mu \rightarrow 0$ this specification collapses to the deterministic choice EUT model, where the choice is strictly determined by the EU of the two lotteries; but as $\mu$ gets larger and larger the choice essentially becomes random. When $\mu=1$ this specification collapses to (C3), where the probability of picking one lottery is given by the ratio of the EU of one lottery to the sum of the EU of both lotteries. Thus $\mu$ can be viewed as a parameter that flattens out the link functions as it gets larger.

An important contribution to the characterization of behavioral errors is the "contextual error" specification proposed by Wilcox [2011]. It is designed to allow robust inferences about the primitive "more stochastically risk averse than," and posits the latent index

$$
\nabla \mathrm{EU}=\left(\left(\mathrm{EU}_{\mathrm{R}}-\mathrm{EU}_{\mathrm{I}}\right) / \nu\right) / \mu
$$

instead of $\left(\mathrm{C}^{\prime}\right)$, where $v$ is a new, normalizing term for each lottery pair $\mathrm{L}$ and $\mathrm{R}$. The normalizing term $\nu$ is defined as the maximum utility over all prizes in this lottery pair minus the minimum utility over all prizes in this lottery pair. The value of $v$ varies, in principle, from lottery choice pair to lottery choice pair: hence it is said to be "contextual." For the Fechner specification, dividing by $v$ ensures that the normalized $\mathrm{EU}$ difference $\left[\left(\mathrm{EU}_{\mathrm{R}}-\mathrm{EU}_{\mathrm{L}}\right) / \nu\right]$ remains in the unit interval. The term $\nu$ does not need to be estimated in addition to the utility function parameters and the parameter for the behavioral error

${ }^{24}$ Some specifications place the error at the final choice between one lottery or after the subject has decided which one has the higher expected utility; some place the error earlier, on the comparison of preferences leading to the choice; and some place the error even earlier, on the determination of the expected utility of each lottery. 
tern, since it is given by the data and the assumed values of those estimated parameters.

The specification employed here is the CRRA utility function from (C1), the Fechner error specification using contextual utility from $\left(\mathrm{C}^{\prime \prime}\right)$, and the link function using the normal CDF from (C4). The log-likelihood is then

$$
\ln \mathrm{L}(\mathrm{r}, \mu ; \mathrm{y}, \mathbf{X})=\sum_{\mathrm{i}}\left[\left(\ln \Phi(\nabla \mathrm{EU}) \times \mathbf{I}\left(\mathrm{y}_{\mathrm{i}}=1\right)\right)+\left(\ln (1-\Phi(\nabla \mathrm{EU})) \times \mathbf{I}\left(\mathrm{y}_{\mathrm{i}}=-1\right)\right)\right]
$$

and the parameters to be estimated are $\mathrm{r}$ and $\mu$ given observed data on the binary choices $\mathrm{y}$ and the lottery parameters in $\mathbf{X}$.

\section{Additional References}

Hey, John D., and Orme, Chris, "Investigating Generalizations of Expected Utility Theory Using Experimental Data,” Econometrica, 62(6), November 1994, 1291-1326.

Wilcox, Nathaniel T., "Stochastic Models for Binary Discrete Choice Under Risk: A Critical Primer and Econometric Comparison," in J. Cox and G.W. Harrison (eds.), Risk Aversion in Experiments (Bingley, UK: Emerald, Research in Experimental Economics, Volume 12, 2008).

Wilcox, Nathaniel T., “'Stochastically More Risk Averse:' A Contextual Theory of Stochastic Discrete Choice Under Risk," Journal of Econometrics, 162(1), May 2011, 89-104. 
Table C1: Estimation Results for Treatments A and B

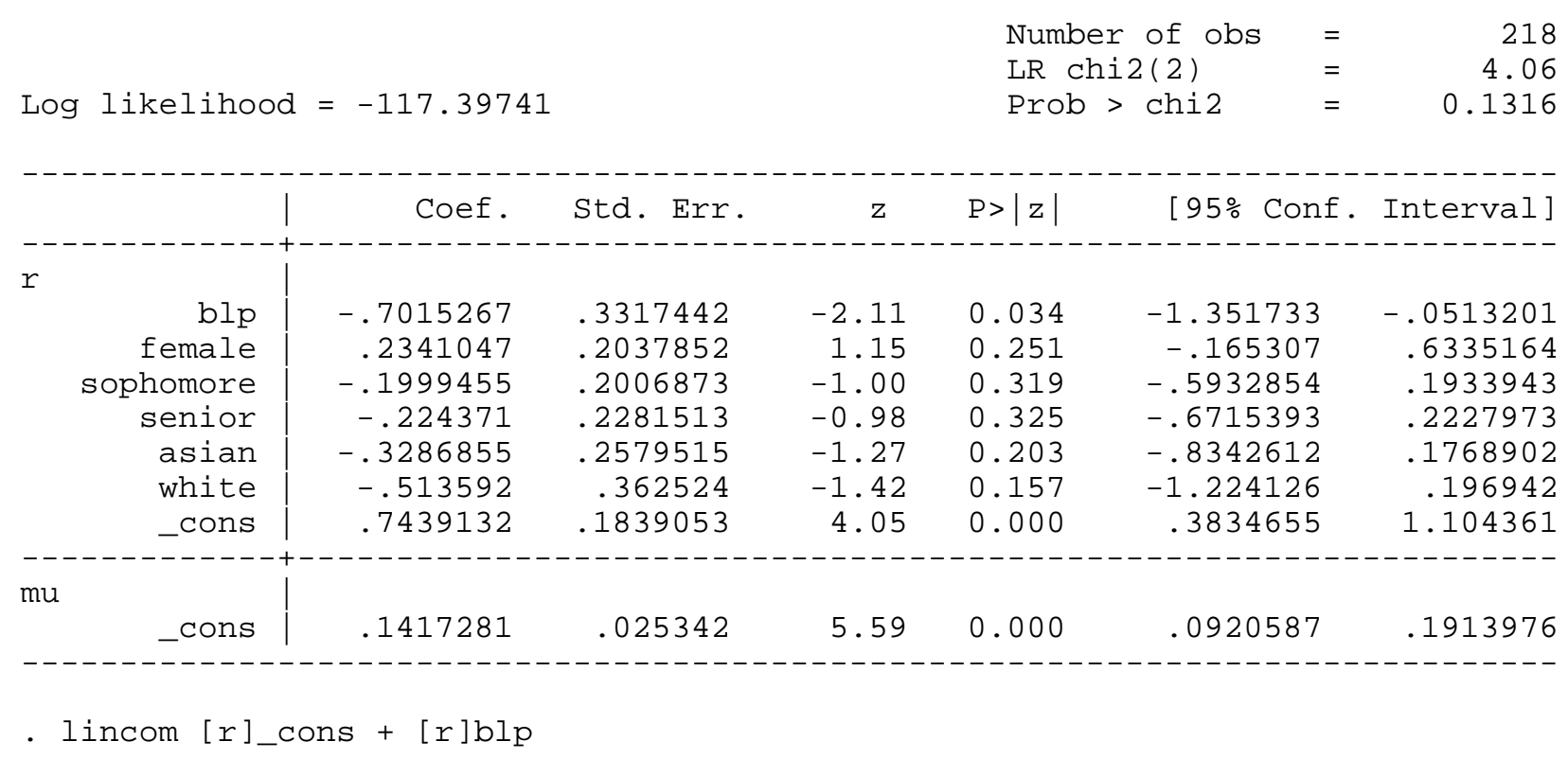

( 1$) \quad[r] b l p+[r] \_$cons $=0$

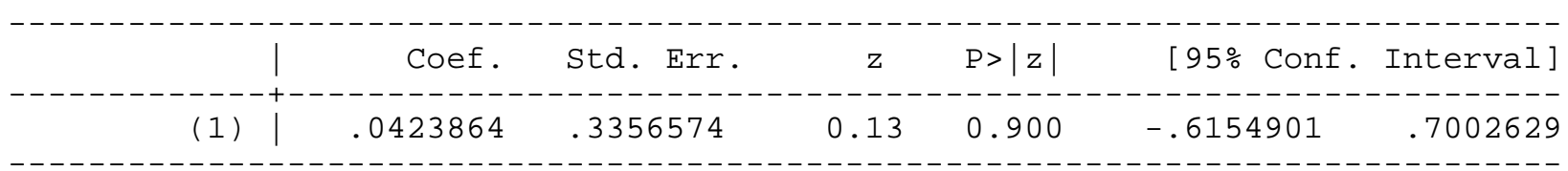

- predictnl r_estimate $=x b(r)$ if e(sample)

- bysort blp: summ r_estimate if e(sample)

$->b l p=0$

\begin{tabular}{|c|c|c|c|c|c|}
\hline riable & Obs & Mean & Std. Dev. & Min & Max \\
\hline r_estimate | & 149 & .6261916 & 2954439 & .0059502 & 9780179 \\
\hline
\end{tabular}

$->$ blp $=1$

\begin{tabular}{|c|c|c|c|c|}
\hline Variable | & Obs & Mean & Std. Dev. & Min \\
\hline r_estimate | & 69 & - . . 0772987 & 2888739 & -.6955765 \\
\hline
\end{tabular}


Table C2: Estimation Results for Treatments A, B, E and F

Log likelihood $=-154.36753$

$\begin{array}{llr}\text { Number of obs } & = & 290 \\ \text { LR chi2(2) } & = & 0.66 \\ \text { Prob }>\text { chi2 } & = & 0.7201\end{array}$

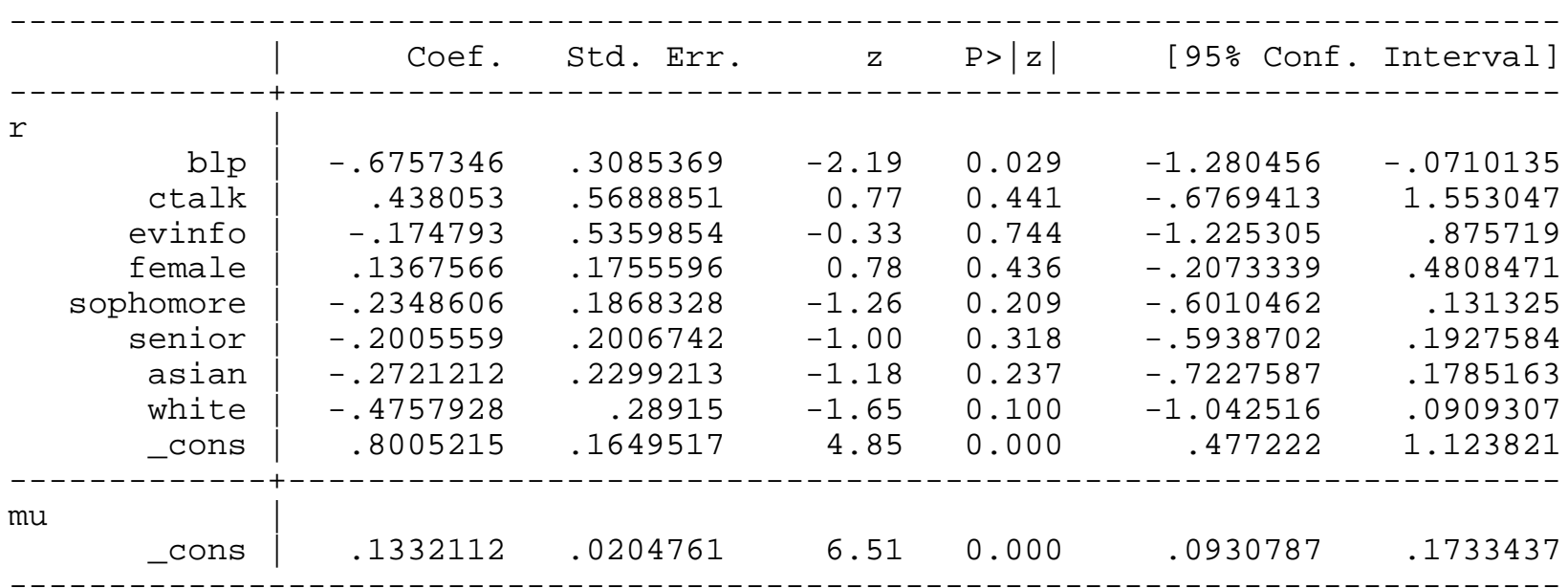

. test ctalk evinfo

(1) $[r] c t a l k=0$

( 2) [r]evinfo $=0$

$$
\begin{aligned}
& \operatorname{chi2}(2)=0.66 \\
& \text { Prob }>\text { chi2 }=0.7191
\end{aligned}
$$

- test blp ctalk evinfo

$\begin{array}{ll}(1) & {[r] b l p=0} \\ (2) & {[r] c t a l k=0} \\ (3) & {[r] \text { evinfo }=0}\end{array}$

$$
\begin{aligned}
\operatorname{chi2}(3)= & 7.67 \\
\operatorname{Prob}>\operatorname{chi} 2= & 0.0534
\end{aligned}
$$

- bysort blp: summ r_estimate if e(sample)

-> blp $=0$

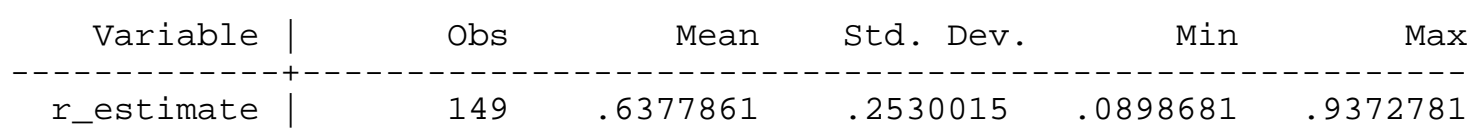

-> blp $=1$

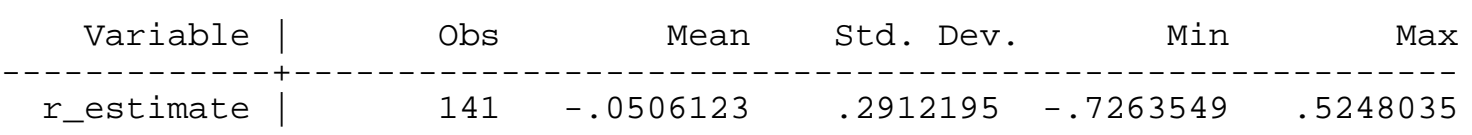


Table C3: Estimation Results for Treatments C and D

$\begin{array}{lllr} & \text { Number of obs } & = & 7590 \\ \text { Log pseudolikelihood }=-4529.7244 & \text { Wald chi2 }(6) & = & 16.02 \\ \text { Prob }>\text { chi2 } & = & 0.0137\end{array}$

(Std. Err. adjusted for 309 clusters in id)

\begin{tabular}{|c|c|c|c|c|c|c|}
\hline & Coef & $\begin{array}{l}\text { Robust } \\
\text { Std. Err. }\end{array}$ & z & $P>|z|$ & {$[95 \%$ Conf } & Interval] \\
\hline \\
\hline blp & -.4760487 & .1585904 & $-3 . \odot \odot$ & $\odot .003$ & -.7868801 & -.1652173 \\
\hline female & .1418673 & .0693712 & 2.05 & 0.041 & .0059023 & .2778323 \\
\hline sophomore & .0168658 & .0812499 & 0.21 & 0.836 & - . 1423811 & .1761126 \\
\hline senior & - . .0787157 & .0742185 & -1.06 & 0.289 & -.2241813 & .0667499 \\
\hline asian & - . .0653329 & .0812816 & -0.80 & 0.422 & -.2246419 & .0939761 \\
\hline white & - . .0๑40662 & .0960593 & -0.04 & 0.966 & -.192339 & .1842066 \\
\hline _cons & .6733916 & .0867036 & 7.77 & $0.0 \odot \odot$ & .5034556 & .8433275 \\
\hline \multirow{2}{*}{\multicolumn{7}{|c|}{1639391}} \\
\hline & .1639391 & .0069316 & 23.65 & $\odot .0 \odot \odot$ & .1503535 & .1775247 \\
\hline
\end{tabular}

- lincom $[r]$ cons $+[r] b l p$

( 1$) \quad[r] b l p+[r] \_$cons $=0$

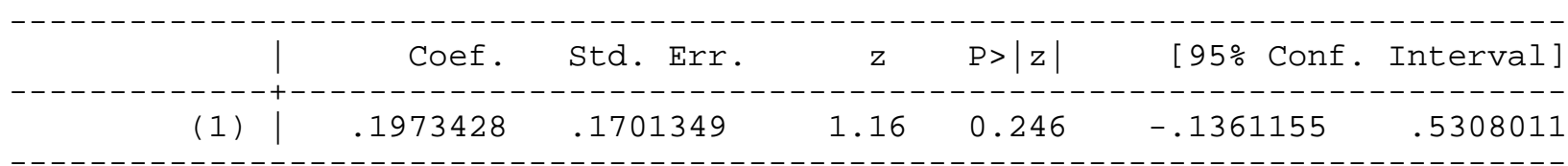

- predictnl $r$ _estimate $1=x b(r)$ if $e($ sample $)$

- bysort blp: summ r_estimate1 if e(sample)

$->b l p=0$

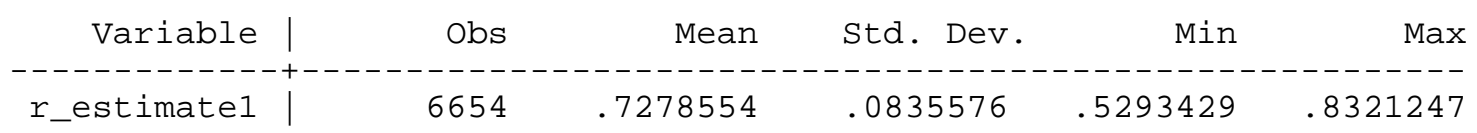

-> blp = 1

\begin{tabular}{|c|c|c|c|c|}
\hline ariable | & Obs & Mean & Std. Dev. & Min \\
\hline r_estimate1 | & 936 & .263594 & .0716006 & .1320099 \\
\hline
\end{tabular}

